\title{
Digital Implementation of a Line Current Shaping Algorithm for Three Phase High Power Factor Boost Rectifier Without Input Voltage Sensing
}

\author{
Souvik Chattopadhyay and V. Ramanarayanan
}

\begin{abstract}
In this paper the implementation of a simple yet high performance digital current mode controller that achieves high power factor operation for three phase boost rectifier is described. The indicated objective is achieved without input voltage sensing and without transformation of the control variables into rotating reference frame. The controller uses the concept of resistance emulation for shaping of input current like input voltage in digital implementation. Two decoupled fixed frequency current mode controllers calculate the switching instants for equivalent single phase boost rectifiers. A combined switching strategy is developed in the form of space vectors to simultaneously satisfy the timing requirements of both the current mode controllers in a switching period. Conventional phase locked loop (PLL) is not required as converter switching is self-synchronized with the input voltage. Analytical formula is derived to obtain the steady state stability condition of the converter. A linear, low frequency, small signal model of the three phase boost rectifier is developed and verified by measurement of the voltage control transfer function. In implementation Texas Instruments's DSP TMS320F240F is used as the digital controller. The algorithm is tested on a $10-\mathrm{kW}, 700-\mathrm{V}$ dc, three phase boost rectifier.
\end{abstract}

Index Terms-Digital current mode controller, DSP(TMS320F240) based implementation, high power factor operation, input voltage sensorless control, three phase boost rectifier.

\section{INTRODUCTION}

B OOST CIRCUIT has emerged as the most widely used topology for three phase high power factor rectification. The high power low switching frequency application such as this is more suitable for digital implementation. The control methods proposed for these converters in recent publications [1]-[3] are all implemented in digital hardware. In digital implementation, the controller for various power hardware configurations and parameter values can be standardized and the protection and control functions can be programmed and tuned. The digital controllers can implement very complex and precise control schemes. It is also insensitive to component

Manuscript received September 10, 2001; revised November 14, 2003. This paper was presented at the APEC'01 Conference, Anaheim, CA, March 4-8, 2001. Recommended by Associate Editor P. K. Jain.

S. Chattopadhyay was with the Power Electronics Laboratory, Department of Electrical Engineering, Indian Institute of Science, Bangalore 560012, India, and is now with the Department of Electrical Engineering, Indian Institute of Technology Madras, Chennai 600036, India (email: souvikc@ee.iitm.ernet.in)

V. Ramanarayanan is with the Power Electronics Laboratory, Department of Electrical Engineering, Indian Institute of Science, Bangalore 560012, India.

Digital Object Identifier 10.1109/TPEL.2004.826494 variations due to temperature changes or aging. Moreover, two basic building blocks of digital hardware, the digital signal processors (DSP) and the analog to digital converters (ADCs), are nowadays available in the same package at affordable cost.

It is shown in [4] that for single-phase full-bridge converter system DSP based controller can implement a pulse-by-pulse current programmed control strategy. In three phase, the control strategy most often employed for Boost rectification controls the active and reactive components of the line current. For this purpose, the sensed currents, after three phase to two phase conversion, need to be transformed from stationary reference frame to the synchronously rotating reference frame [5] of line frequency, so that they appear as dc quantities to the closed loop controller. As a result a phase locked loop (PLL) becomes a necessity, which is not so easy to design, if various nonidealities like frequency variation and distortions in the line voltage waveform as would be present in a real life system, are to be taken into account.

A few power factor correction strategies have been proposed in literature that do not require input voltage sensors. The virtual flux direct power control (VF-DPC) [2] is structurally similar to the well known direct torque control (DTC). The switching frequency of the VF-DPC is not constant and the sampling frequency needs to be much higher than the switching frequency. As a result fast ADCs and microprocessors are required for digital implementation of the scheme. In comparison, the power factor correction method proposed in this paper is based on constant switching frequency and low sampling frequency. It has been implemented using low speed digital hardware such as DSP TMS320F240 (20 MHz-6.6 $\mu \mathrm{s} A D C)$. The other input voltage sensorless method proposed in [3] has the structure of a voltage oriented control (VOC). In comparison, the control structure of the method proposed in this paper is simpler because there are no current error amplifiers and input voltage observers in the control loop. This scheme has eliminated the need for transforming any quantity from stationary reference frame to synchronously rotating reference frame. As a consequence the PLL is not required.

The control objective is defined by this controller as: shape the line current like line voltage. This would ensure high power factor operation of the rectifier. To achieve that first, two decoupled fixed frequency current mode controllers are used to determine the switching states of the converter. Subsequently this information is processed to obtain the switching duty ratios of a three phase full bridge converter. 


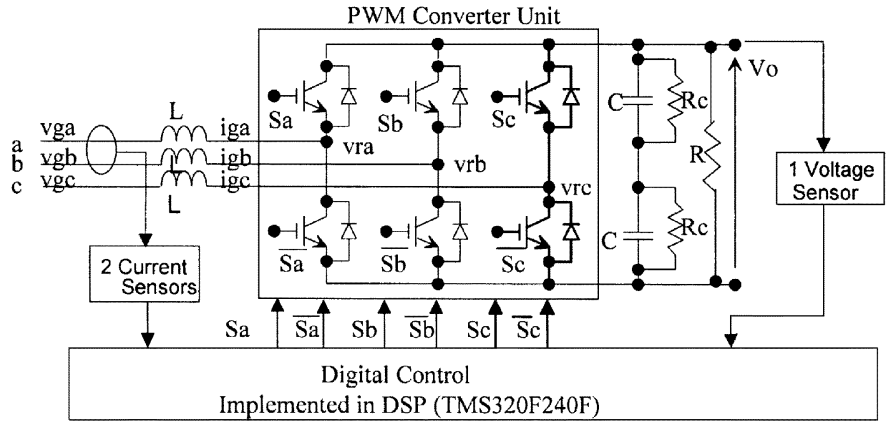

Fig. 1. Power and control schematic of the three phase high power factor boost rectifier with the digital controller implemented in DSP TMS320F240.

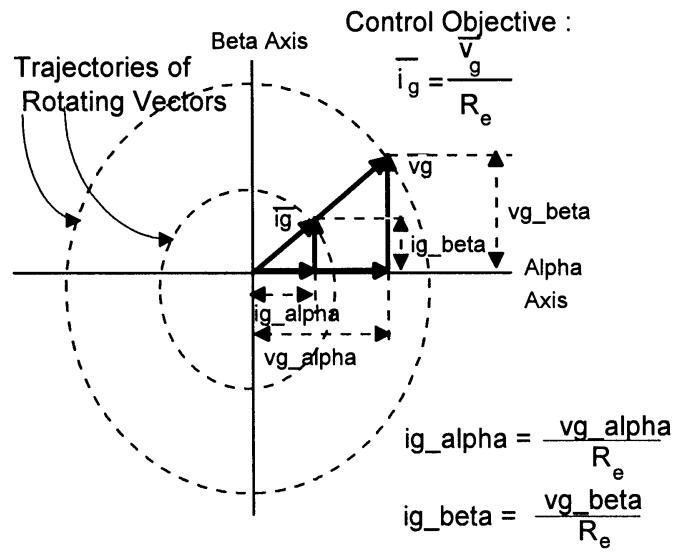

Fig. 2. Control objectives in alpha and beta axes.

\section{CONTROLLER}

We can define the control objective of a three phase high power factor Boost rectifier, shown in Fig. 1, as

$$
\overline{i_{g}}=\frac{\overline{v_{g}}}{R_{e}}
$$

where $R_{e}$ is the emulated resistance of the rectifier. The $\left(^{-}\right)$ above a variable indicates a space phasor. The mathematical description of the input voltage vector is

$$
\overline{v_{g}}=v_{g a}+v_{g b} e^{j \frac{2 \pi}{3}}+v_{g c} e^{\frac{j 4 \pi}{3}}=v_{g \alpha}+j v_{g \beta} .
$$

The current vector needs to be scaled by $2 / 3$ inorder to maintain power balance between input and output

$$
\overline{i_{g}}=\frac{2}{3}\left(i_{g a}+i_{g b} e^{j \frac{2 \pi}{3}}+i_{g c} e^{j \frac{4 \pi}{3}}\right)=i_{g \alpha}+j i_{g \beta} .
$$

If we take components along $\alpha$ and $\beta$ axes, which are stationary and orthogonal to each other, the control objective can be expressed in terms of two scalar equations

$$
\begin{aligned}
i_{g \alpha} & =\frac{v_{g \alpha}}{R e} \\
i_{g \beta} & =\frac{v_{g \beta}}{R e}
\end{aligned}
$$

as shown in Fig. 2.

Equations (4) and (5) can be employed as the control objectives of two single phase Boost converters, one in $\alpha$ axis and the other in $\beta$ axis. We may consider that the input supply consists of two independent single phase ac sources, $v_{g \alpha}$ and $v_{g \beta}$ and

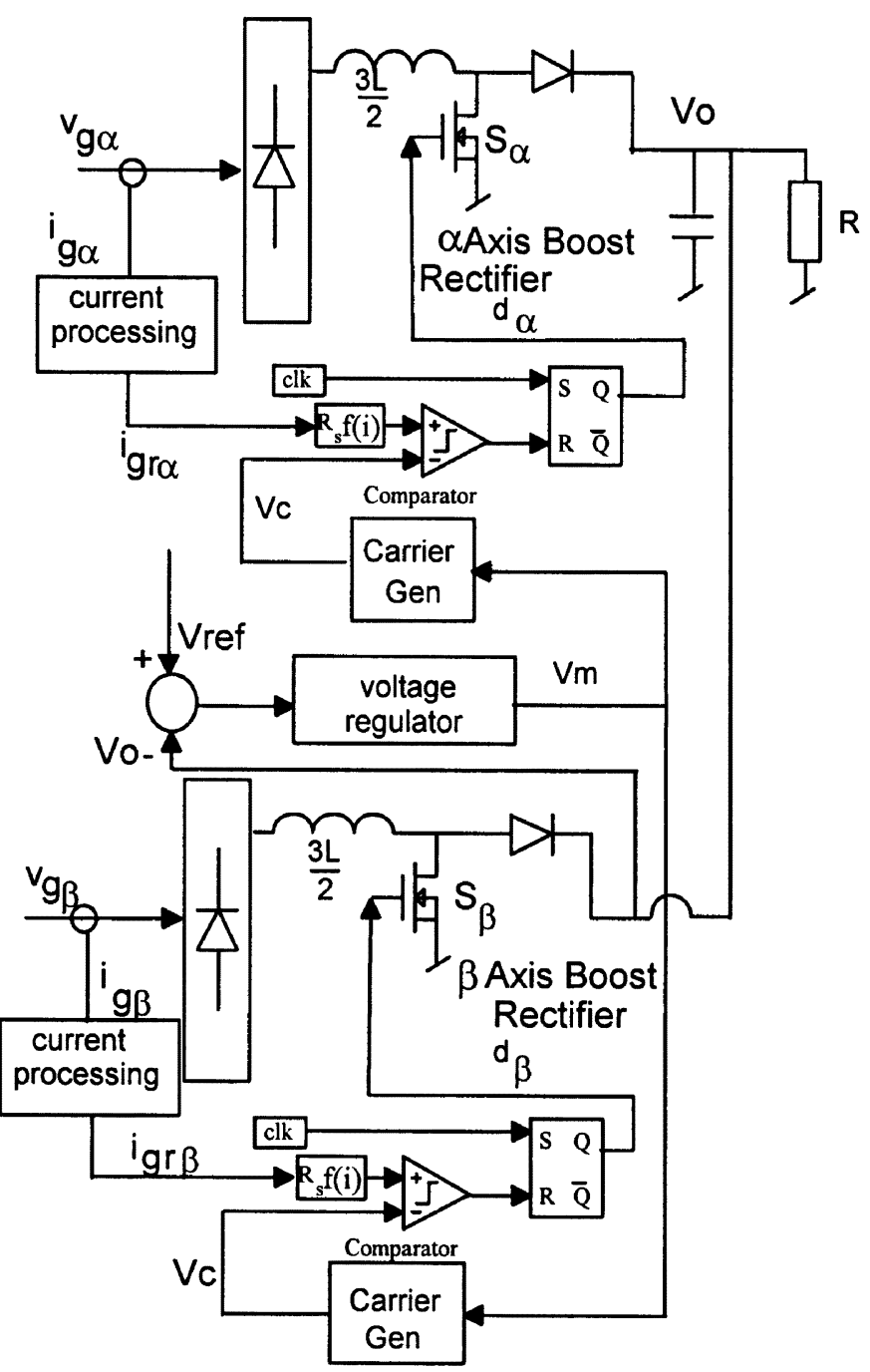

Fig. 3. Functional representation of three phase high power factor boost rectifier with two independent single phase rectifiers in current mode control structure.

the output of the rectifier is $V_{o}$, same as the output of the three phase rectifier. The input currents $i_{g \alpha}$ and $i_{g \beta}$ should be made proportional to the respective input voltages $v_{g \alpha}$ and $v_{g \beta}$. From the point of view of the control objective in $(\alpha, \beta)$ reference frame, the circuit schematics of Fig. 1 and Fig. 3 are equivalent.

Let us assume that the duty ratios $d_{\alpha}$ and $d_{\beta}$ of these two switches $Q_{\alpha}$ and $Q_{\beta}$ can be independently controlled. Therefore we can write the continuous conduction mode input-output conversion equations for the two independent boost rectifiers as

$$
\begin{aligned}
& v_{\text {gr } \alpha}=\left(1-d_{\alpha}\right) V_{o} \\
& v_{g r \beta}=\left(1-d_{\beta}\right) V_{o}
\end{aligned}
$$

$V_{o}$ is the regulated output voltage of the three phase rectifier.

Since $d_{\alpha}$ and $d_{\beta}$ are both positive quantities we need to use $\mathrm{dc}$ variables $v_{g r \alpha}$ and $v_{g r \beta}$ in (6) and (7). Similarly $i_{g r \alpha}$ and $i_{g r \beta}$ are dc variables obtained after rectification of $i_{g \alpha}$ and $i_{g \beta}$. By using (6) and (7) the control objective can be reformulated as

$$
\begin{aligned}
& i_{\text {gr } \alpha}=\frac{V_{o}\left(1-d_{\alpha}\right)}{R e} \\
& i_{g r \beta}=\frac{V_{o}\left(1-d_{\beta}\right)}{R e} .
\end{aligned}
$$


Conceptually this is equivalent to two current sources charging the same capacitor for voltage output.

The duty ratio of the $\alpha$ and $\beta$ axis rectifiers may be obtained as

$$
\begin{aligned}
& d_{\alpha}=\left(1-\frac{i_{g r \alpha} R e}{V_{o}}\right) \\
& d_{\beta}=\left(1-\frac{i_{g r \beta} R e}{V_{o}}\right) .
\end{aligned}
$$

Scaling down the output voltage and the emulator resistance to the control level $\left(V_{o} / R_{e}=V_{m} / R_{s}\right)$ we get

$$
\begin{aligned}
& d_{\alpha}=\left(1-\frac{i_{g r \alpha} R_{s}}{V_{m}}\right) \\
& d_{\beta}=\left(1-\frac{i_{g r \beta} R_{s}}{V_{m}}\right)
\end{aligned}
$$

$V_{m}$ is the output voltage of the modulator and $R_{s}$ is the current sense resistance. Under closed loop $V_{m}$ becomes the output of the outer loop voltage error amplifier. Depending of the samples of the $i_{g r}$ employed, we may identify peak current, average current and end of the period current controls. These functions of current are generalized in Fig. 3 as $f(i)$.

In continuous time domain, $i_{g r \alpha}$ and $i_{g r \beta}$ can be made to represent peak current [6], average current [7], or end of the period current [8] of the inductor in every switching period $T_{s}$. The effect of these switching strategies on inductor current is shown in Fig. 4(a)-(c), respectively. However, for simple digital implementation, we would like to select a control strategy that does not require the current to be sampled at a rate higher than the switching frequency. Therefore, unless the sampling instant in a period is varied, as in [9], the control objectives shown in Fig. 4(a) or (b) can not be implemented. In contrast, the switching law shown in Fig. 4(c) is very convenient for digital implementation, because the sampling instant can be kept fixed at the beginning of every switching period. From (12) and (13) we can calculate the duty ratios $d_{\alpha}[n]$ and $d_{\beta}[n]$ for the " $n$ " th switching period as

$$
\begin{aligned}
& d_{\alpha}[n]=\left(1-\frac{i_{g r \alpha e}[n-1] R_{s}}{V_{m}}\right) \\
& d_{\beta}[n]=\left(1-\frac{i_{g r \beta e}[n-1] R_{s}}{V_{m}}\right) .
\end{aligned}
$$

The suffix " $e$ " in (14) and (15) indicates that the current is sampled at the end of the switching period. It should be noted that the current at the end of period $[n-1]$ is same as the current at the beginning of period $[n]$. So $i_{g r \alpha}[n]=i_{\text {grae }}[n-1]$ and $i_{g r \beta}[n]=i_{g r \beta e}[n-1]$. This is shown in Fig. 4(d). The control law can therefore be expressed as

$$
\begin{aligned}
& d_{\alpha}[n]=\left(1-\frac{i_{g r \alpha}[n] R_{s}}{V_{m}}\right) \\
& d_{\beta}[n]=\left(1-\frac{i_{g r \beta}[n] R_{s}}{V_{m}}\right) .
\end{aligned}
$$

Evaluation of $d_{\alpha}[n]$ and $d_{\beta}[n]$ for the period " $n$ " is shown in Fig. 5.

In the three phase bridge converter eventually the switch combination $\left(S_{a}, S_{b}, S_{c}\right)$ has to be evaluated from the duty ratio variables $d_{\alpha}[n]$ and $d_{\beta}[n]$. The conversion of $d_{\alpha}[n]$ and $d_{\beta}[n]$

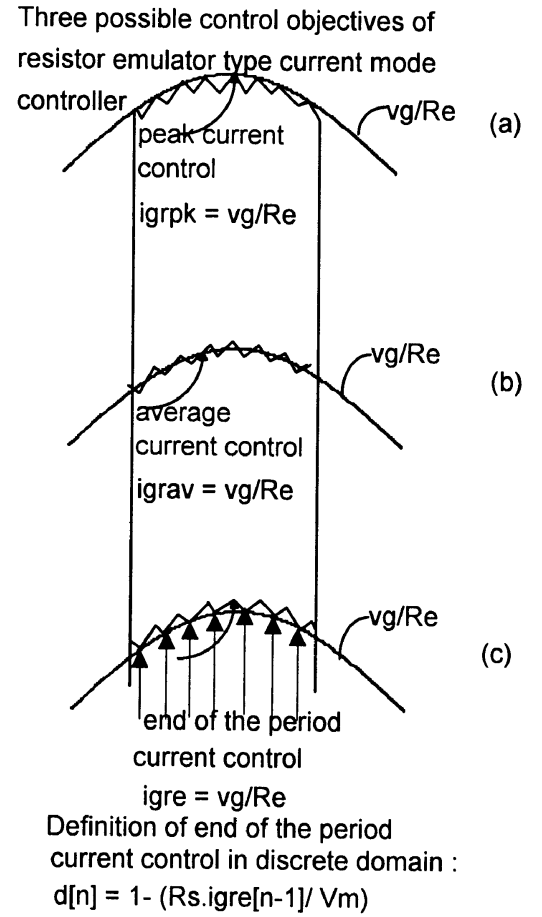

igre[n-1] : current at the end of $(n-1)$ th period $\operatorname{igr}[n]$ : current at the beginning of $n$th period $\operatorname{igr}[n]=\operatorname{igre}[n-1]$

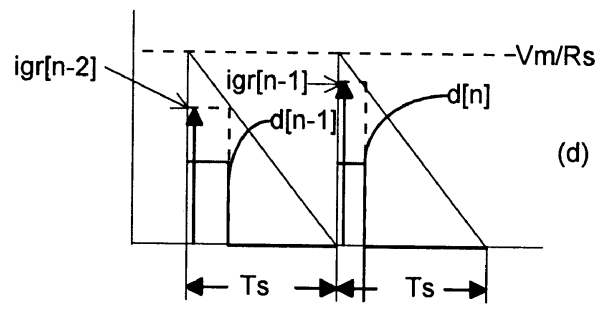

Fig. 4. Resistor emulator digital current mode controller.

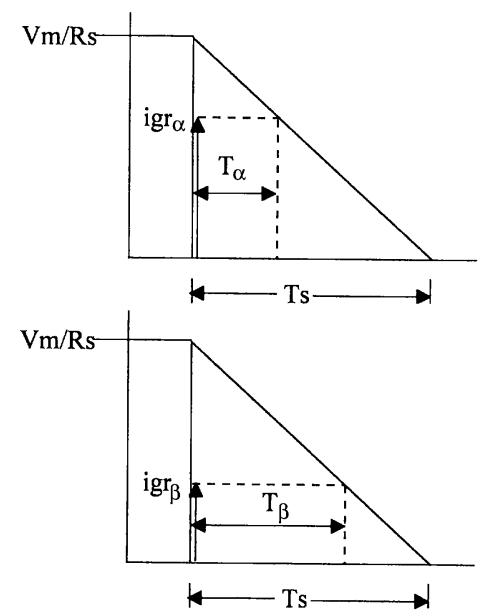

Fig. 5. Evaluation of $d_{\alpha}[n]$ and $d_{\beta}[n]$ for the period " $n$."

to active vector durations $T_{1}[n]$ and $T_{2}[n]$ using space vector approach is taken up next. The space vectors produced by $\left(S_{a}\right.$, $\left.S_{b}, S_{c}\right)$ are shown in Fig. 6. Effectively they produce six active vectors $\left(\overline{V_{1}}, \overline{V_{2}}, \ldots, \overline{V_{6}}\right)$ of magnitude $V_{o}$ and a null vector $\left(\overline{V_{o}}\right.$, $\left.\overline{V_{7}}\right)$. The sectors, $(1,2, \ldots, 6)$, that is the space between two 


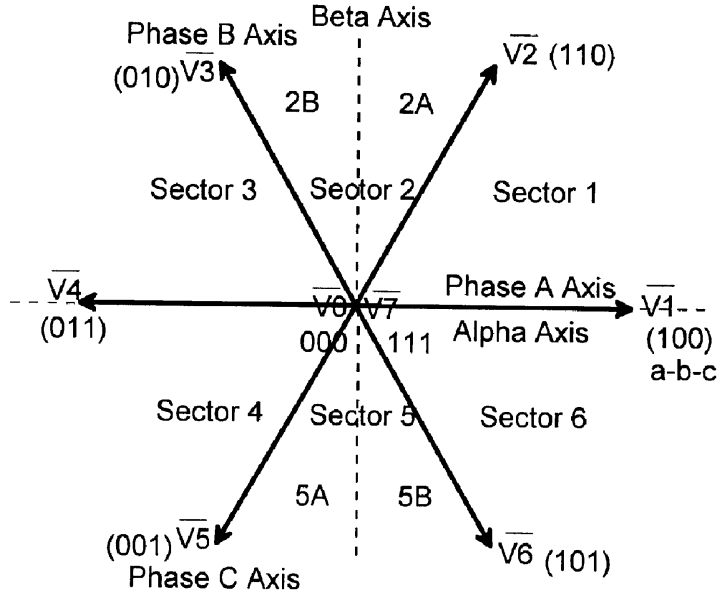

Fig. 6. Voltage vectors produced by PWM converter. The sector definitions are also given.

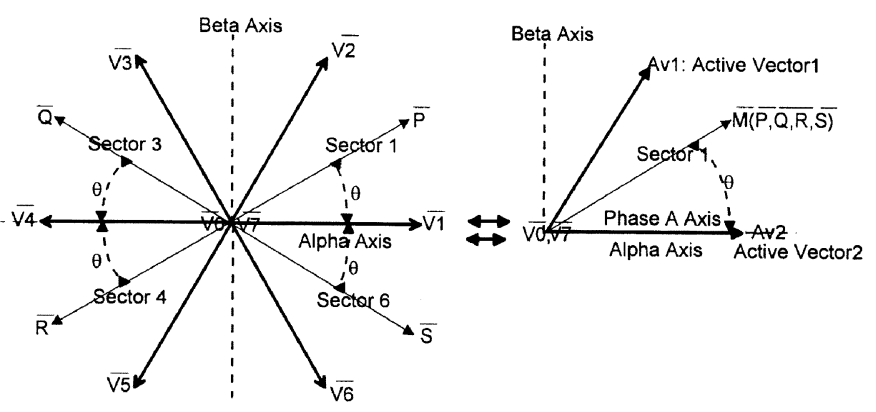

Fig. 7. Mapping of $\bar{P}, \bar{Q}, \bar{R}, \bar{S}$ vectors into $\bar{M}$ in sector 1 of positive alpha-beta axis for solution of $\mathrm{T} 1$ and $\mathrm{T} 2$; for example: $\overline{A_{v 1}}=\overline{V_{3}}$ and $\overline{A_{v 2}}=\overline{V_{4}}$ for vector $\bar{Q}$.

active vectors, are also defined in the same figure. The strategy of relating $\left(S_{a}, S_{b}, S_{c}\right)$ to $S_{\alpha}$ and $S_{\beta}$ uses the fact that the volt-second excitation to the inductors are same at the $(\alpha, \beta)$ reference frame. In sector 1 , the active vectors used for switching are $\overline{V_{2}}$ for duration $T_{1}$ and $\overline{V_{1}}$ for duration $T_{2}$. The volt-second excitation for the $(\alpha, \beta)$ axis inductors with the active vectors $A_{v 1}\left(=\overline{V_{2}}\right)$ and $A_{v 2}\left(=\overline{V_{1}}\right)$ may be equated as

$$
\begin{aligned}
\frac{T_{1}[n]}{2}+T_{2}[n] & =\left(1-d_{\alpha}[n]\right) T_{s} \\
\frac{\sqrt{3}}{2} T_{1}[n] & =\left(1-d_{\beta}[n]\right) T_{s} .
\end{aligned}
$$

The switching time transformations valid for sector 1 has to be extended for the sectors $1,3,4$, and 6 of the $(\alpha, \beta)$ plane. This is done as follows. Consider the input voltages at $(\bar{P}, \bar{Q}, \bar{R}, \bar{S})$ with an angle $\theta$ with respect to the $\alpha$ axis of the segment, as shown in Fig. 7. The same may be located at $\bar{M}$ and $T_{1}[n]$ and $T_{2}[n]$ may be obtained. However the active vectors will be different for different sectors. The active vectors $A_{v 1}$ and $A_{v 2}$ for sectors $1,3,4$, and 6 are identified as in Table I.

The active vectors employed for input voltage vector in sector $2 \mathrm{~A}$ are $A_{v 1}=\overline{V_{2}}$, switched for duration $T_{1}$ and $A_{v 2}=\overline{V_{3}}$, switched for duration $T_{2}$. The volt-second excitation for the
TABLE I

Selection of $A_{v 1}$ AND $A_{v 2}$ IN SECtor $1,3,4$, AND 6

\begin{tabular}{c|c|c}
\hline Sector & $A_{v 1}$ & $A_{\nu 2}$ \\
\hline 1 & $\overline{V_{2}}$ & $\overline{V_{1}}$ \\
\hline 3 & $\overline{V_{3}}$ & $\overline{V_{4}}$ \\
\hline 4 & $\overline{V_{5}}$ & $\overline{V_{4}}$ \\
\hline 6 & $\overline{V_{6}}$ & $\overline{V_{1}}$ \\
\hline
\end{tabular}

TABLE II

Selection of $A_{v 1}$ AND $A_{v 2}$ IN SECtor 2A, 2B, 5A, AND 5B

\begin{tabular}{c|c|c}
\hline Sector & $A_{v 1}$ & $A_{v 2}$ \\
\hline $2 A$ & $\overline{V_{2}}$ & $\overline{V_{3}}$ \\
\hline $2 B$ & $\overline{V_{3}}$ & $\overline{V_{2}}$ \\
\hline $5 A$ & $\overline{V_{5}}$ & $\overline{V_{6}}$ \\
\hline $5 B$ & $\overline{V_{6}}$ & $\overline{V_{5}}$ \\
\hline
\end{tabular}

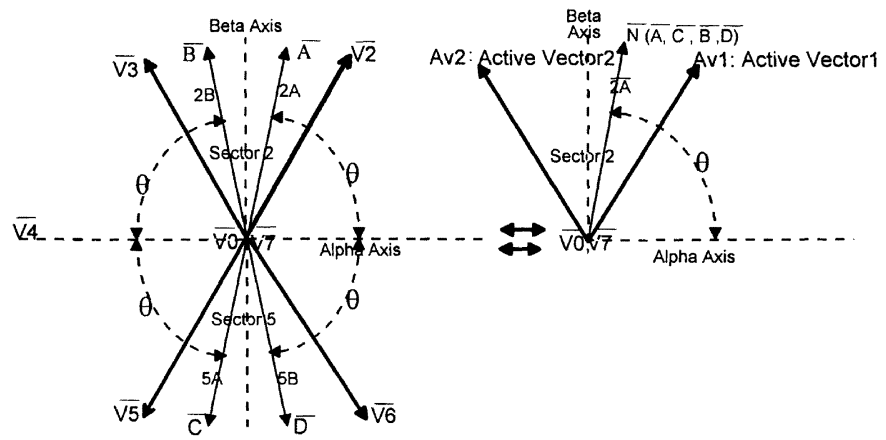

Fig. 8. Mapping of $\bar{A}, \bar{B}, \bar{C}, \bar{D}$ vectors into $\bar{N}$ in Sector $2 \mathrm{~A}$ of positive alpha-beta axis for solution of T1 and T2; For example: $\overline{A_{v 1}}=\overline{V_{2}}$ and $\overline{A_{v 2}}=$ $\overline{V_{3}}$ for vector $\bar{A}$ whereas $\overline{A_{v 1}}=\overline{V_{3}}$ and $\overline{A_{v 2}}=\overline{V_{2}}$ for vector $\bar{B}$ mode controller.

$(\alpha, \beta)$ axis inductors with the active vectors $A_{v 1}\left(=\overline{V_{2}}\right)$ and $A_{v 2}\left(=\overline{V_{3}}\right)$ may be equated as

$$
\begin{aligned}
\frac{1}{2} T_{1}[n]-\frac{1}{2} T_{2}[n] & =\left(1-d_{\alpha}[n]\right) T_{s} \\
\frac{\sqrt{3}}{2} T_{1}[n]+\frac{\sqrt{3}}{2} T_{2}[n] & =\left(1-d_{\beta}[n]\right) T_{s} .
\end{aligned}
$$

Similarly for sectors $2 A, 2 B, 5 A$, and $5 B$, Table II gives the selection of vectors. Any vector $\bar{A}, \bar{B}, \bar{C}, \bar{D}$ in those sectors can be mapped as $\bar{N}$ in the positive-positive quadrant, as shown in Fig. 8, for the solution of $T_{1}[n]$ and $T_{2}[n]$. The remaining time of the period $\left(T_{0}[n]=T_{s}-T_{1}[n]-T_{2}[n]\right)$ should be utilized by the null vector.

The current processing function of the modulator is as follows. First, the two phase currents $i_{g a}[n]$ and $i_{g b}[n]$ are sensed and converted to $i_{g \alpha}[n]$ and $i_{g \beta}[n]$ by standard three phase to two phase transformation

$$
\begin{aligned}
& i_{g \alpha}[n]=i_{g a}[n] \\
& i_{g \beta}[n]=\frac{1}{\sqrt{3}}\left(2 i_{g b}[n]+i_{g a}[n]\right) .
\end{aligned}
$$


TABLE III

GENERATION OF RECTIFIED CURRENT VARIABLES $i_{g r \alpha}[n]$ AND $i_{g r \beta}[n]$

\begin{tabular}{c|c|c}
\hline Sector & $i_{g r a}[n]$ & $i_{g r \beta}[n]$ \\
\hline 1 & $i_{g a}[n]$ & $i_{g \beta}[n]$ \\
\hline $2 A$ & $i_{g a}[n]$ & $i_{g \beta}[n]$ \\
\hline $2 B$ & $-i_{g a}[n]$ & $i_{g \beta}[n]$ \\
\hline 3 & $-i_{g a}[n]$ & $i_{g \beta}[n]$ \\
\hline 4 & $-i_{g a}[n]$ & $-i_{g \beta}[n]$ \\
\hline $5 A$ & $-i_{g a}[n]$ & $-i_{g \beta}[n]$ \\
\hline $5 B$ & $i_{g a}[n]$ & $-i_{g \beta}[n]$ \\
\hline 6 & $i_{g a}[n]$ & $-i_{g \beta}[n]$ \\
\hline
\end{tabular}

However the modulators work on dc quantities, so based on the sector information, we generate the rectified current variables $i_{g r \alpha}[n]$ and $i_{g r \beta}[n]$ from Table III, and use them in (16) and (17) for calculation of duty ratios.

It can be seen that input voltage need not be sensed for computation of $T_{1}[n]$ and $T_{2}[n]$. However the sector information should be known for appropriate selection of active vectors (Table I and Table II), and also for rectification of input current (Table III). This controller implements self-synchronization of the converter switching with respect to line voltage based on the following logic: as long as the sector selection is correct, the $\alpha$ and $\beta$ axis modulators will produce duty ratios less than 1 , i.e., $d_{\alpha}[n]<1$ or $d_{\beta}[n]<1$. Further $T_{2}[n]>0$ also has to be true for the modulator to operate in the correct sector. When any one of these conditions are violated, the next sector in sequence is chosen, as shown in Fig. 9. This sector change can take place in the same switching cycle in which invalid duty ratio solutions were obtained because of initial incorrect selection of sectors. The change will continue in sequence until valid solutions are obtained. The modulator will produce appropriate switching signals only after latching to the correct sector.

\section{SimUlation}

The proposed controller is simulated on MATLABSIMULINK (version 5.3) software platform. The nominal rating of the three phase Boost rectifier is chosen to be $10 \mathrm{Kw}$, $415 \mathrm{Vac}, 700 \mathrm{Vdc}$. The inductance/phase in simulation is $6 \mathrm{mH} /$ phase and the switching frequency of the converter is $10 \mathrm{KHz}$. The block diagram of the overall system as well as the subsystems are shown in Fig. 10. The power circuit of the three phase Boost rectifier has been modeled in its ideal form as a system with six inputs and four outputs. The inputs are three line voltages and three basic ON/OFF switching signals. The outputs are three line currents and the rectified dc voltage. The relationship between input-output variables can be expressed by a set of differential and algebraic equations. These equations are given in Appendix I with reference to the circuit schematic of Fig. 1 and are used in simulating the power circuit. The digital controller has three inputs: two phase currents and the rectified dc voltage. The inputs are sampled at the rate of $10 \mathrm{KHz}$. Three ON/OFF signal for the switches are obtained

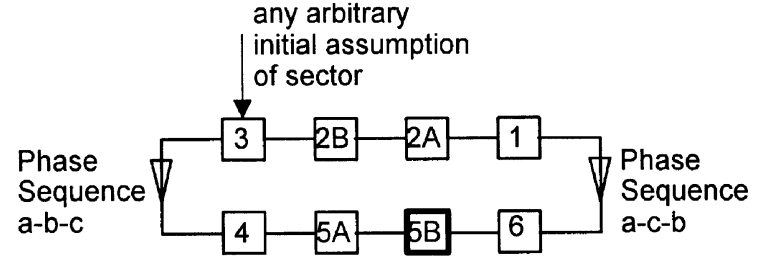

Fig. 9. Sequence of sector change to be followed to eventually synchronize with the location of voltage vector: for example if the voltage vector is in sector $5 \mathrm{~B}$ and the initial assumption of sector is 3 then 3,4 and $5 \mathrm{~A}$ will not produce acceptable solution but the modulator will lock at sector 5B (A-B-C).

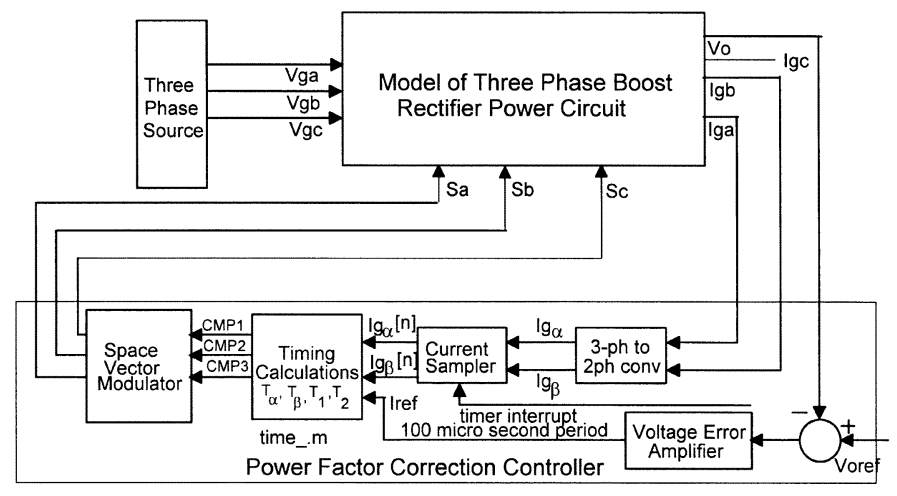

Fig. 10. Block diagram of the power factor correction controller in simulation (SIMULINK).

as outputs from the controller. The digital current mode controllers for $\alpha$ and $\beta$ axes and the subsequent space vector implementation of a combined switching strategy have been simulated using the equations derived in the previous section. The time calculations based on (18)to (21) are performed by a MATLAB program named "time_.m." The simulation results of Fig. 11 show waveforms of $v_{g a}, i_{g a}$, and $v_{0}$ at quarter, half, and full loads.

\section{Steady State Stability}

The current mode control may exhibit steady state stability problem under certain operating conditions because of the presence of a local feedback in its control structure [10]. In this section we derive the steady state stability limit of the digitally controlled three phase boost rectifier described in Section II by analysis of an equivalent single phase boost rectifier. The analysis is graphical in nature and is basically the same as has been used for a current programmed dc-dc converter in [10]. It has been assumed in the derivation that, under quasi steady state condition, the inductor current at the end of a switching period is same as the current at the beginning of that period. This assumption is valid because the switching frequency of the converter is much higher than the line frequency.

Let $i_{g}$ be the current in the inductor at the beginning of the switching period $T_{s}$, as shown in Fig. 12. If there is a perturbation $\Delta i_{g 1}$ in $i_{g}$ due to some reason, then it would change duty ratio of that period. Therefore at the end of the same switching period the current will not come back to its steady state value $i_{g}$. In general we can say that at the end of the switching period $T_{s}$ the perturbation would propagate by an amount $\Delta i_{g 2}$. For 

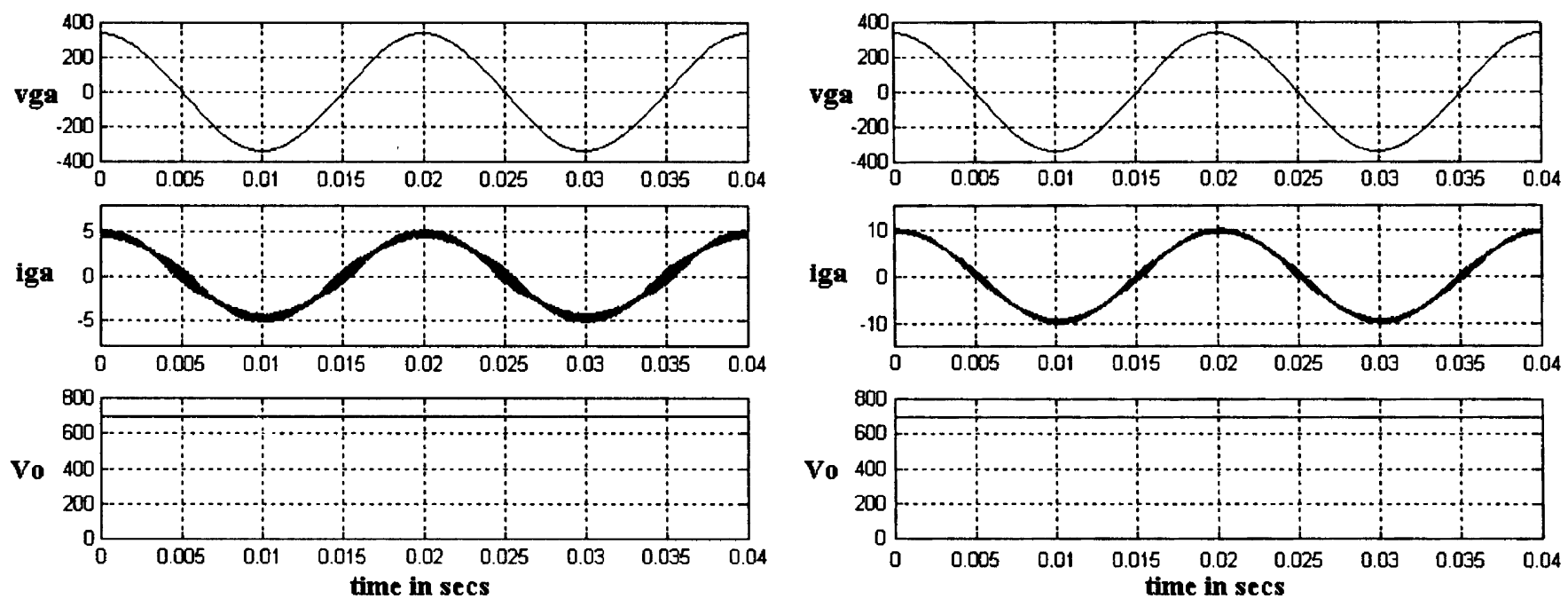

(a)

(b)
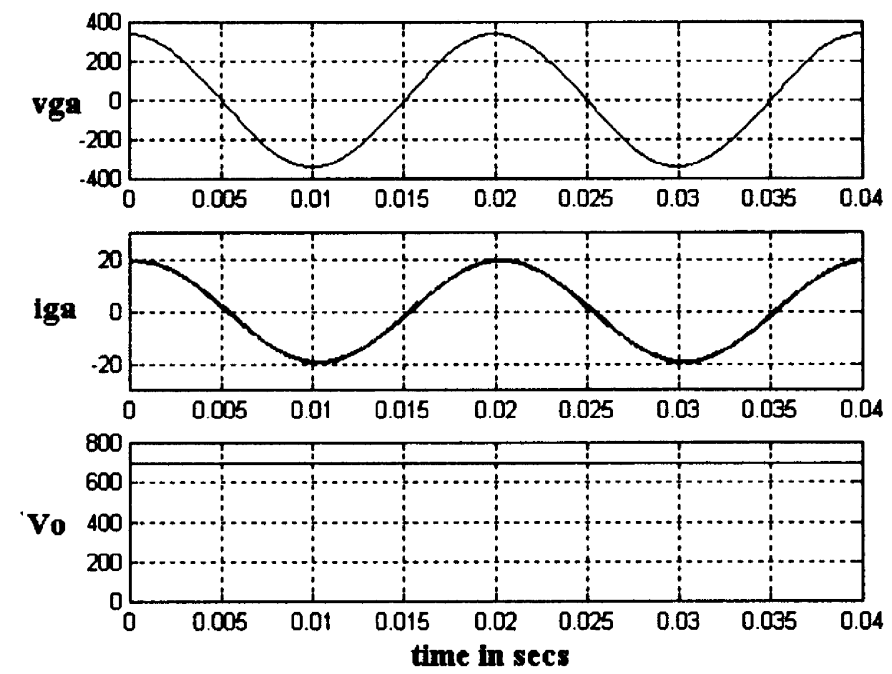

(c)

Fig. 11. Simulation results of the three phase boost rectifier at different loads: (a) input phase voltage $\left(v_{g a}\right)$, input phase current $\left(i_{g a}\right)$ and output voltage $\left(V_{o}\right)$ at $R=200 \Omega$, (b) input phase voltage $\left(v_{g a}\right)$, input phase current $\left(i_{g a}\right)$ and output voltage $\left(V_{o}\right)$ at $R=100 \Omega$, and (c) input phase voltage $\left(v_{g a}\right)$, input phase current $\left(i_{g a}\right)$ and output voltage $\left(V_{o}\right)$ at $R=50 \Omega$.

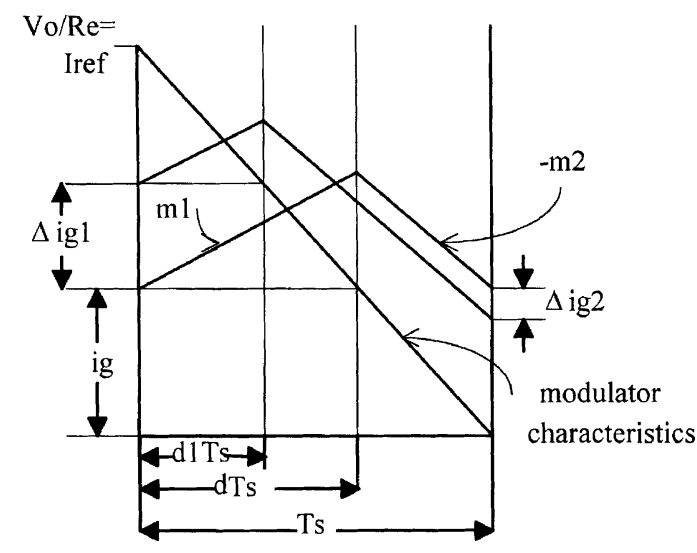

Fig. 12. Derivation of the steady state stability condition for the discrete implementation of resistor emulator type current mode controller.

steady state stability condition to be fulfilled the magnitude of $\Delta i_{g 2}$ should be less than the magnitude of $\Delta i_{g 1}$.
The steady state condition for the inductor current is given by

$$
m_{1} d=m_{2}(1-d)
$$

where $m_{1}$ is the ON state slope, $m_{2}$ is the OFF state slope, in a switching period $T_{s}$ and $d$ is the steady state duty ratio as shown in Fig. 12. The duty ratio of the period under perturbed condition is $d_{1}$

$$
\begin{aligned}
m_{1} & =\frac{2 v_{g}}{3 L} \\
m_{2} & =\frac{2\left(V_{o}-v_{g}\right)}{3 L} \\
d_{1} & =d-\frac{\Delta i_{g 1}}{I_{\text {ref }}}=d-\frac{\Delta i_{g 1} R e}{V_{o}} .
\end{aligned}
$$

If $\Delta i_{g 2}$ is the deviation in current at the end of the period, then it can be expressed as

$$
\begin{aligned}
\Delta i_{g 2} & =\Delta i_{g 1}+m_{1} d_{1} T_{s}-m_{2}\left(1-d_{1}\right) T_{s} \\
& =\Delta i_{g 1}-\left(m_{1}+m_{2}\right) \frac{\Delta i_{g 1}}{I_{r e f}} T s .
\end{aligned}
$$



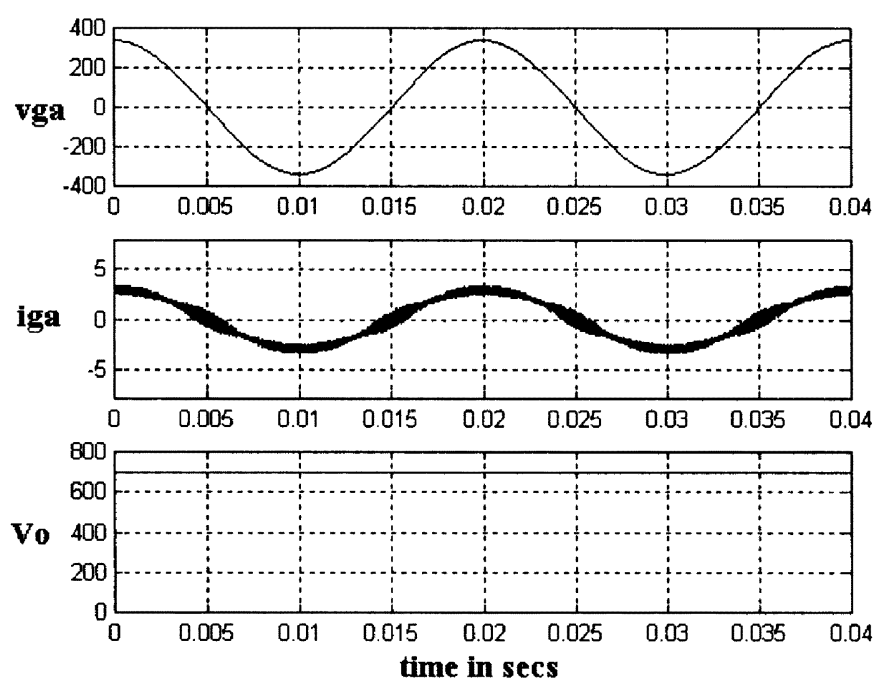

(a)
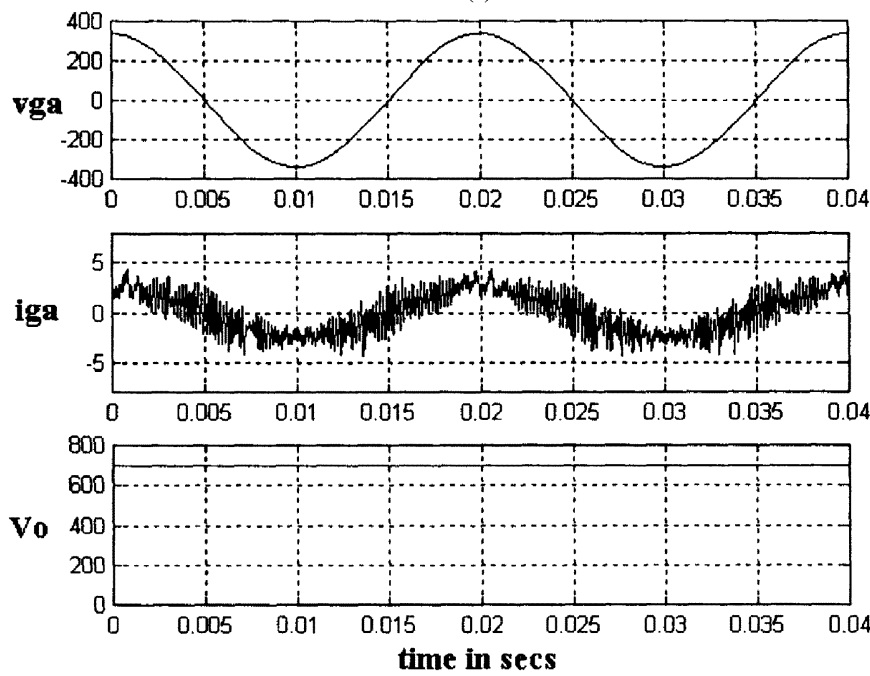

(b)

Fig. 13. Simulation results of the converter verifying the steady state stability analysis (a) input phase voltage $\left(v_{g a}\right)$, input phase current $\left(i_{g a}\right)$ and output voltage $\left(V_{o}\right)$ at $R=325 \Omega(\mathrm{b})$ input phase voltage $\left(v_{g a}\right)$, input phase current $\left(i_{g a}\right)$ and output voltage $\left(V_{o}\right)$ at $R=375 \Omega$. The analysis predicts steady state stability limit at $R=340 \Omega$ for $L=6 \mathrm{mH}, T_{s}=100 \mu \mathrm{S}, M_{g}=.726$.

Let us define $M_{g}$ as the ratio of the peak input voltage to the output voltage

$$
M_{g}=\frac{V_{g m}}{V_{o}} ; \text { where } V_{g m}=v_{g \alpha}(\max )=v_{g \beta}(\max )
$$

and the relationship between $R_{e}$ and $R$ is obtained from the power balance condition

$$
2\left(\frac{V_{g m}^{2}}{2 R e}\right)=\frac{V_{o}^{2}}{R} ; \quad \text { or }, \quad R e=M_{g}^{2} R .
$$

$R$ is the load resistance of the boost rectifier. The load resistance of the equivalent single phase rectifier is $2 R$ since both the $\alpha$ axis and $\beta$ axis rectifiers charge the output capacitor in parallel. Similarly from voltage $\left(v_{g a}=1.5 v_{g a}\right)$ and power balance $\left(i_{g a}=i_{g a}\right)$ conditions we get $(3 / 2) L$ as the inductance of the equivalent single phase rectifier, where $L$ is the per phase inductance of the three phase system.

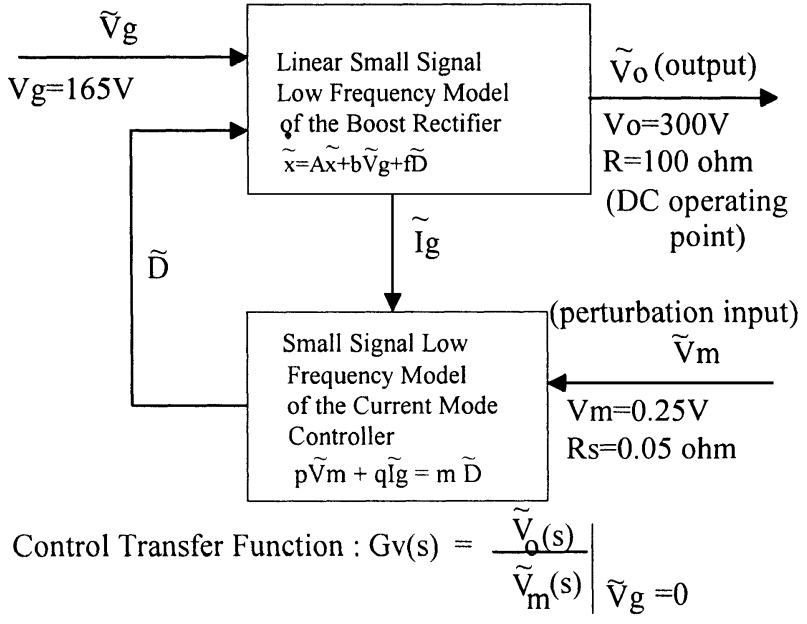

Fig. 14. Voltage control transfer function $G_{v}(s)$ for linear, low frequency, small signal model of the three phase boost rectifier.

Using (25), (26), and (30), the ratio between $\Delta i_{g 2}$ and $\Delta i_{g 1}$ can be obtained from (28) as

$$
\frac{\Delta i_{g 2}}{\Delta i_{g 1}}=1-\frac{2 M_{g}^{2} R T_{s}}{3 L}
$$

If $\left(2 M_{g}^{2} R T_{s} / 3 L\right)>2$ then $\left|\Delta i_{g 2} / \Delta i_{g 1}\right|>1$ and in subsequent cycles the deviation in current from steady state value $i_{g}$ will not diminish. Therefore steady state stability is ensured if (32) is satisfied

$$
R<\frac{3 L}{M_{g}^{2} T_{s}} .
$$

The analysis predicts steady state stability limit $R=340 \Omega$ for $L=6 \mathrm{mH}, T_{s}=100 \mu \mathrm{S}, M_{g}=0.726$. The simulation results of Fig. 13(a) and (b) are presented for $R=325 \Omega$ and $R=375 \Omega$, respectively. It can be seen that the input current is steady state stable for $R=325 \Omega$ but not so for $R=375 \Omega$.

\section{Small Signal Low Frequency Model}

The objective of this section is to develop a low frequency, small signal, linear model of the three phase high power factor boost rectifier switched by the digital controller described in Section II. In [11], linearized, small signal model of a three phase boost rectifier has been derived in $d-q$ reference frame by transforming all the states into rotating reference frame of line frequency, so that the states appear as dc quantities under steady state. In contrast the small signal model developed here is based on the current mode control structure in the stationary reference frame of $(\alpha, \beta)$ coordinates. With the assumption of low modulating frequency and selection of an appropriate nominal operating point, the number of state variables of the converter has been reduced in this model compared to $d-q$ axis model.

The final objective is to find out the voltage control transfer function $G_{v}(s)=\widetilde{V_{o}}(s) / \widetilde{V_{m}}(s)$ of the boost rectifier. $G_{v}(s)$ is necessary for the design of the voltage error amplifier. The variables used in this analysis are denoted by capital letters (nominal as well as dc) and small signal deviation by ${ }^{\sim}$ on the top of the symbol. It can be seen from Fig. 14 that the external small signal 


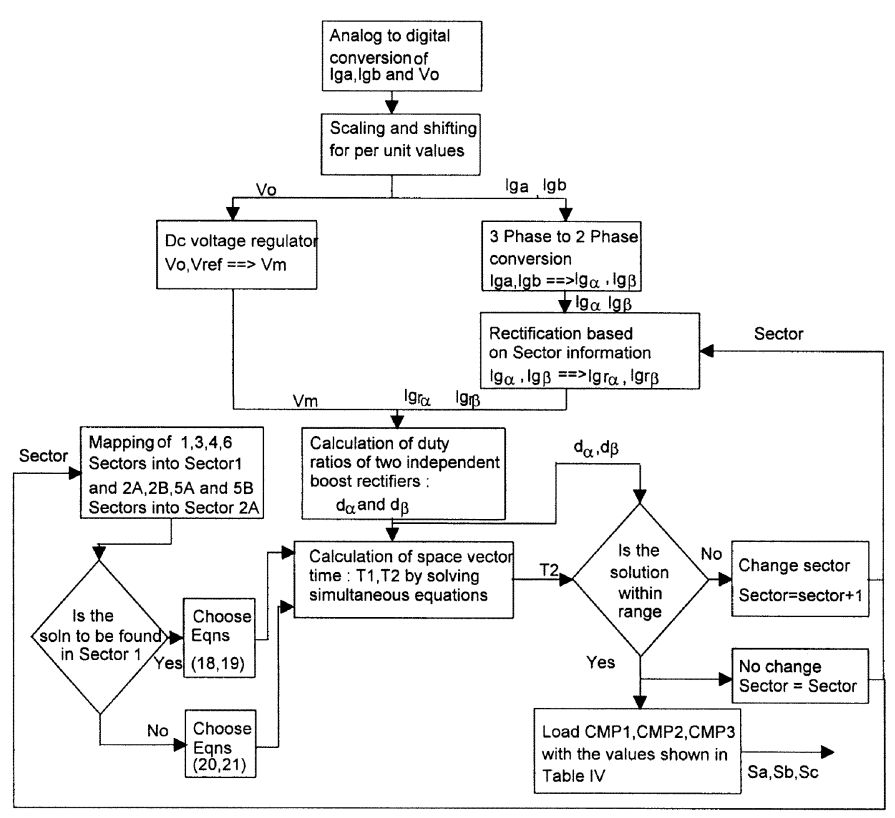

Fig. 15. Flow chart of the control algorithm implemented in TMS $320 \mathrm{~F} 240$ DSP for resistor emulator type line current shaping controller.

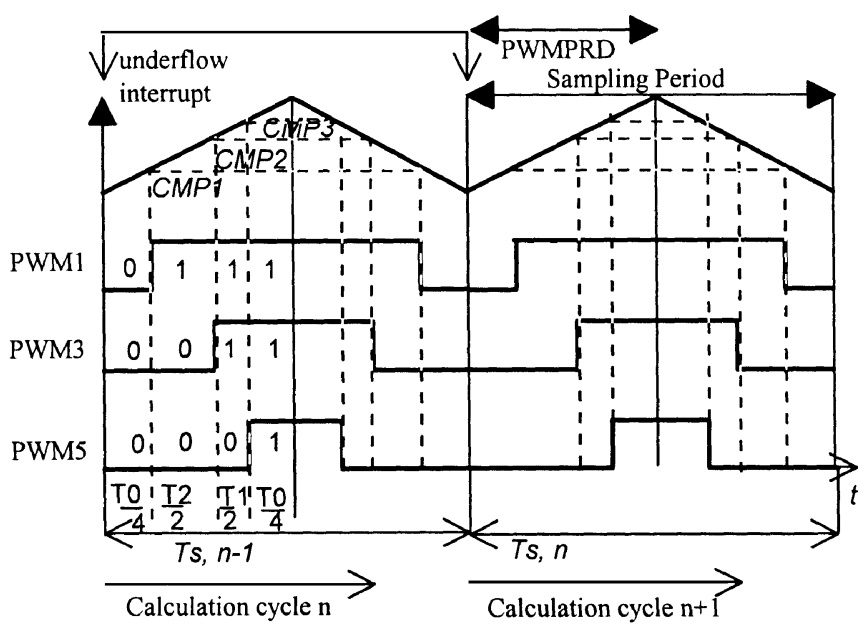

Fig. 16. Generation of symmetrical PWM signals using Full Compare Unit of the TMS320F240 DSP Controller

TABLE IV

COMPARE REGISTER VALUES FOR SYMMETRIC PWM GENERATION

\begin{tabular}{l|l|l|l}
\hline Sector & \multicolumn{1}{|c|}{$C M P 1$} & \multicolumn{1}{c|}{$C M P 2$} & \multicolumn{1}{c}{$C M P 3$} \\
\hline 1 & $T_{x}=\left(T_{s}-T_{1}-T_{2}\right) / 2$ & $T_{x}+T_{2}$ & $T_{x}+T+T$ \\
\hline $2 A$ & $T_{x}+T_{2}$ & $T_{x}=\left(T_{s}-T_{1}-T_{2}\right) / 2$ & $T_{x}+T_{2}+T_{1}$ \\
\hline $2 B$ & $T_{x}+T_{1}$ & $T_{x}=\left(T_{s}-T_{1}-T_{2}\right) / 2$ & $T_{x}+T_{2}+T_{1}$ \\
\hline 3 & $T_{x}+T_{2}+T_{1}$ & $T_{x}=\left(T_{s}-T_{1}-T_{2}\right) / 2$ & $T_{x}+T_{1}$ \\
\hline 4 & $T_{x}+T_{2}+T_{1}$ & $T_{x}+T_{1}$ & $T_{x}=\left(T_{s}-T_{1}-T_{2}\right) / 2$ \\
\hline $5 A$ & $T_{x}+T_{1}$ & $T_{x}+T_{2}+T_{1}$ & $T_{x}=\left(T_{s}-T_{1}-T_{2}\right) / 2$ \\
\hline $5 B$ & $T_{x}+T_{2}$ & $T_{x}+T_{2}+T_{1}$ & $T_{x}=\left(T_{s}-T_{1}-T_{2}\right) / 2$ \\
\hline 6 & $T_{x}=\left(T_{s}-T_{1}-T_{2}\right) / 2$ & $T_{x}+T_{2}+T_{1}$ & $T_{x}+T_{2}$ \\
\hline
\end{tabular}

input to the modulator is $\widetilde{V_{m}}$ and the output is the duty ratio variation $\widetilde{D} . \widetilde{I}_{g}$ also acts as small signal input to the modulator since the current mode control has inner closed loop in its structure. The small signal model of the three phase boost rectifier is
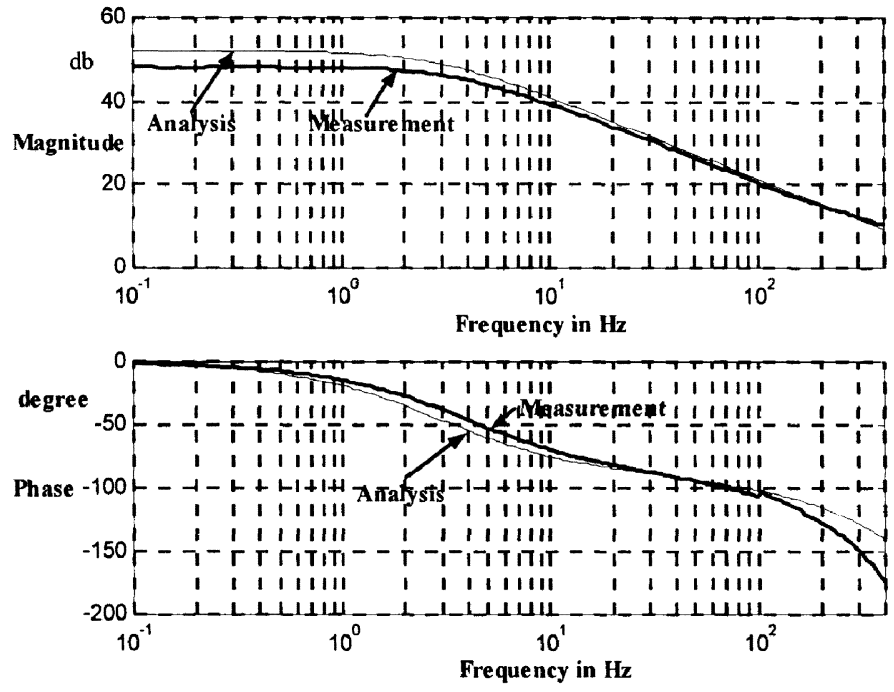

Fig. 17. Frequency response plot of voltage control transfer function $G_{v}(s)=$ $\widetilde{V_{o}}(s) / \widetilde{V_{m}}(s) ; V_{\text {ga }}$ (phase $)=110 \mathrm{~V}(\mathrm{rms}), V_{o}=300 \mathrm{~V}, V_{m}=0.25 \mathrm{~V}$ $L=7.5 \mathrm{mH} /$ phase, $R=100 \Omega, C=1650 \mu \mathrm{F}, R_{s}=0.05 \Omega$.

derived from the equivalent functional representation of Fig. 3 . The inductor currents of the $\alpha$ and $\beta$ axis converters charge the same capacitor. So we can write

$$
\begin{aligned}
\frac{3}{2} L \frac{d I_{g r \alpha}}{d t} & =V_{g r \alpha}-\left(1-D_{\alpha}\right) V_{o} \\
\frac{3}{2} L \frac{d I_{g r \beta}}{d t} & =V_{g r \beta}-\left(1-D_{\beta}\right) V_{o} \\
C \frac{d V_{o}}{d t} & =\left(1-D_{\alpha}\right) I_{g r a}+\left(1-D_{\beta}\right) I_{g r \beta}-\frac{V_{o}}{R} .
\end{aligned}
$$

We assume that the input voltages are sinusoidal and balanced. Then the power input to the three phase boost rectifier is same at any instant of the line cycle and equal to the output power. We therefore can choose any instant as the nominal operating point before perturbing the variables by small amount compared to the nominal value for the development of the small signal model of the converter. However, it is convenient to choose $V_{g r \alpha}=V_{g r \beta}=1.5 V_{g a \max } \sin \left(45^{\circ}\right)=V_{g}$ as the nominal operating point representing one fourth of the entire line cycle. Then, the input currents being proportional to input voltages, are given by $I_{g r \alpha}=I_{g r \beta}=I_{g a \max } \sin \left(45^{\circ}\right)=I_{g}$. From (8) and (9) we get $D_{\alpha}=D_{\beta}=D$. The small signal linear model of the converter is therefore given by

$$
\begin{aligned}
\frac{3}{2} L \frac{\widetilde{d I_{g}}}{d t} & =\widetilde{V_{g}}-(1-D) \widetilde{V_{o}}+V_{o} \widetilde{D} \\
C \frac{\widetilde{d V_{o}}}{d t} & =2(1-D) \widetilde{I_{g}}-2 I_{g} \widetilde{D}-\frac{\widetilde{V_{o}}}{R} .
\end{aligned}
$$

The steady state values are

$$
\begin{aligned}
V_{o} & =\frac{V_{g}}{(1-D)} \\
I_{g} & =\frac{V_{g}}{(1-D)^{2} 2 R} .
\end{aligned}
$$



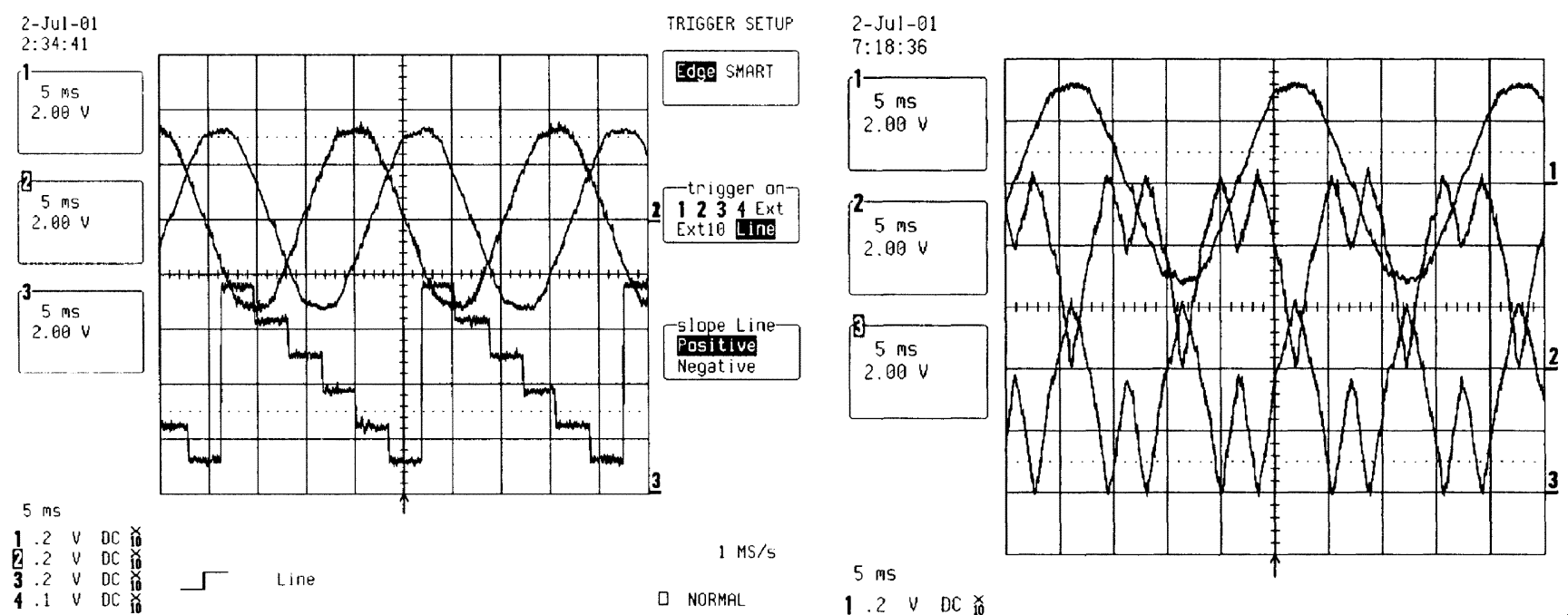

5 ms

$1.2 \cup$ DC $\times$

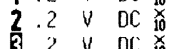

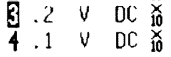

2-Jul-OI
$5: 39: 48$

$2.09 \mathrm{~ms}$
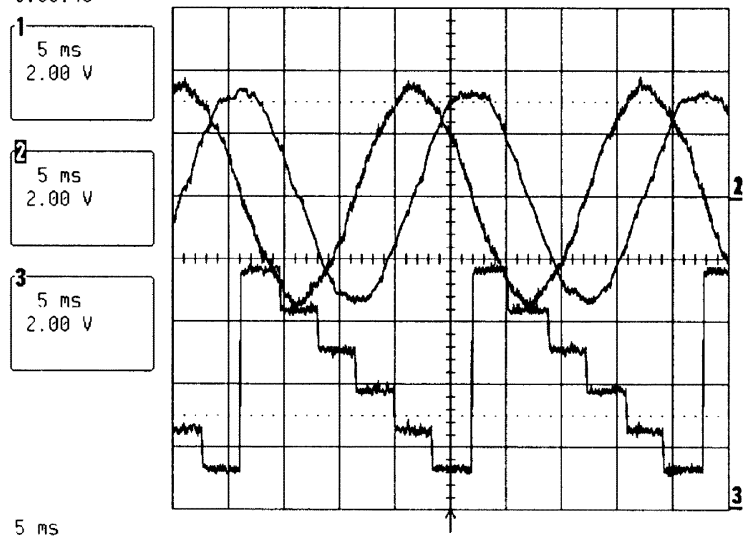

5 mS

$1.2 \cup D C$ io

$2.2 \vee$ DC 葆

$3.2 \checkmark$ DC 8 in Line

$4.1 \cup$ OC

(b)
$1 \mathrm{MS} / \mathrm{s}$

口 NORMAL

Fig. 18. Experimental results at $V_{a b}=415 \mathrm{~V}$ and $V_{o}=700 \mathrm{~V}$ (a) $i_{g a}$ (ch1), $i_{g b}(\mathrm{ch} 2)$ and sector-1 to 6 (ch3) and (b) $i_{g \alpha}(\mathrm{ch} 1), i_{g \beta}(\mathrm{ch} 2)$ and sector (ch3). Current scale: $12.5 \mathrm{~A} / \mathrm{div}$. Sector scale: each sector is equivalent to 0.625 division.

The dc and small signal linear model of the modulator are given by

$$
\begin{aligned}
& D=1-\frac{I_{g} R_{s}}{V_{m}}=1-\frac{V_{g} R_{s}}{(1-D)^{2} 2 R V_{m}} \\
& \widetilde{D}=\frac{(1-D)}{V_{m}} \widetilde{V_{m}}-\frac{R_{s} \widetilde{I_{g}}}{V_{m}} .
\end{aligned}
$$

The steady state outputs $D$ and $V_{0}$ as function of steady state inputs $V_{g}$ and $V_{m}$ are given by

$$
\begin{aligned}
D & =1-\left(\frac{V_{g} R_{s}}{V_{m} 2 R}\right)^{\frac{1}{3}} \\
V_{o} & =V_{g}^{\frac{2}{3}}\left(\frac{V_{m} 2 R}{R_{s}}\right)^{\frac{1}{3}} .
\end{aligned}
$$

In digital implementation of the modulator the current is sensed at the beginning of the switching cycle. So in a very strict sense the sensed current $I_{g e}$ is not exactly equal to the average current $I_{g}$ of that period. However in order to keep the derivation simple

2-Jul-BI

7:13:06

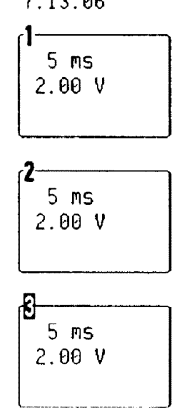

5 ms

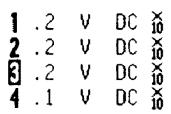

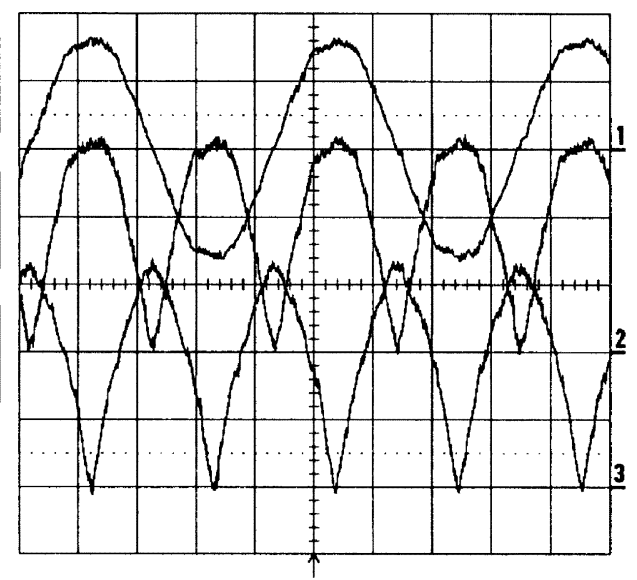

(a)

Q NORMAL

(b)

D NORMAL

Fig. 19. Experimental results at $V_{a b}=415 \mathrm{~V}$ and $V_{o}=700 \mathrm{~V}$ (a) $i_{g a}$ (ch1), $T_{1}(\operatorname{ch} 2)$ and $T_{2}(\operatorname{ch} 3)$ and (b) $i_{g a}(\operatorname{ch} 1), T_{\alpha_{-} o f f}(\operatorname{ch} 2)$ and $T_{\beta_{-} o f f}(\operatorname{ch} 3)$. Current scale: $12.5 \mathrm{~A} / \mathrm{div}$. Time scale: $24 \mu \mathrm{s} / \mathrm{div}$.

we have ignored the effect of ripple on the inductor current and used the approximation $I_{g} \approx I_{g e}$. Now we can follow the same procedure as described in [12] to replace $\widetilde{D}$ by the RHS of (41) and subsequently by eliminating $\widetilde{I_{g}}$ by $\widetilde{V_{m}}$ and $\widetilde{V_{o}}$ we can determine the voltage control transfer function as

$\frac{\widetilde{V_{o}}(s)}{\widetilde{V_{m}}(s)}=\frac{\frac{1}{3}\left[\left(\frac{V_{g}}{V_{m}}\right)^{2}\left(\frac{2 R}{R_{s}}\right)\right]^{\frac{1}{3}}\left[1-\left(\frac{V_{m} 2 R}{V_{g} R_{s}}\right)^{\frac{2}{3}}\left(\frac{3 L}{4 R}\right) s\right]}{\left[1+s\left(\frac{L}{4 R}\left(\frac{V_{m} 2 R}{V_{g} R_{s}}\right)^{\frac{2}{3}}+\frac{R C}{3}\right)+s^{2} \frac{L C}{4}\left(\frac{V_{m} 2 R}{V_{g} R_{s}}\right)^{\frac{2}{3}}\right]}$

\section{Digital IMPLEMENTATION IN TMS320F240}

The control algorithm is implemented in Texas Instruments DSP TMS320F240. The current mode control calculations for the two axes are performed in software each time the control 


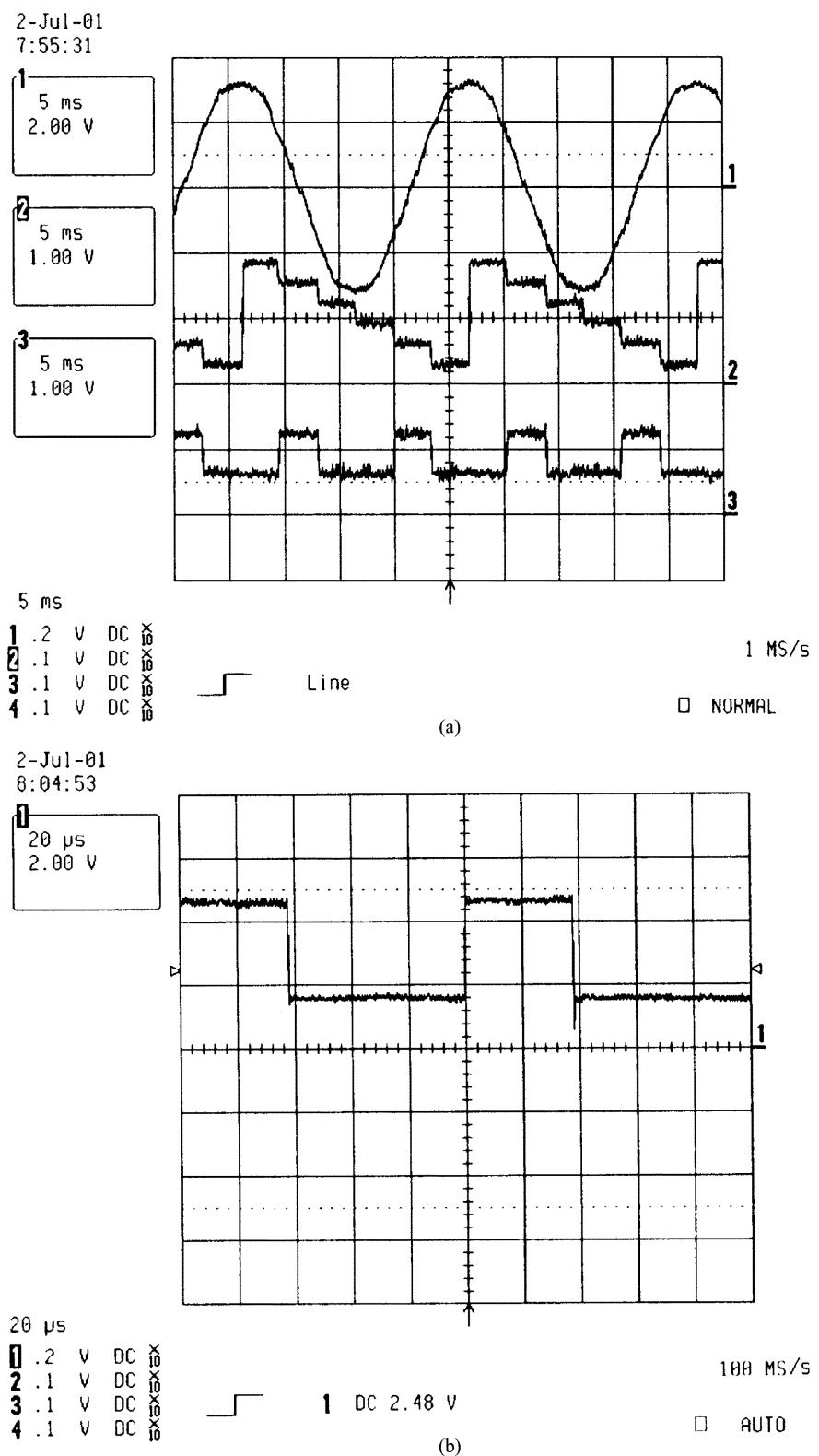

Fig. 20. Experimental results at $V_{a b}=415 \mathrm{~V}$ and $V_{o}=700 \mathrm{~V}$ (a) $i_{g a}$ (ch1), sector (ch2) and a signal (ch3) showing the mapping all sectors into sector 1 (low) and sector 2A (high) Current Scale: $12.5 \mathrm{~A} / \mathrm{div}$ and (b) Control loop time shown as signal high duration (ch1).

loop is executed. The flowchart of the controller is shown in Fig. 15.

The Event Manager module in the peripheral library of TMS320F240 provides necessary hardware support for the generation of PWM pulses for the switching devices of the three phase Boost rectifier. The general purpose (GP) timer 1 [13] of the Event Manager Module is configured in the initialization part of the program to work in continuous up-down counting mode for the generation of symmetric waveform as shown in Fig. 16. The timer 1 is clocked by CPU clock CPUCLK at $20 \mathrm{MHz}$. The timer 1 period register T1PR is loaded with a constant PWMPRD $=1000$, corresponding to $50 \mu$ s. In the up-down counting mode it generates a triangle waveform of frequency $10 \mathrm{KHz}$. The execution of the control loop is initiated by the GP timer1 underflow interrupt, i.e., when the timer counter reaches $0000 \mathrm{H}$, that has a period of $100 \mu \mathrm{s}$. In each underflow interrupt the dual 10-b analog to digital converter module (ADC) of the TMS320F240 measures two phase currents and the dc output voltage. The current conversions are simultaneous in the two ADCs followed by $\mathrm{dc}$ output voltage conversion thus requiring a total conversion time of $13.2 \mu(=6.6 \mu * 2) \mathrm{s}$. The current mode controllers receive as input the output of the dc voltage regulator. The duration for which each switch of the three phase converter is to be turned $\mathrm{ON}$ is computed from the timing results of the two current mode controllers. These values are loaded to the Full Compare Units of the Event Manager Module. The Full Compare Unit [13] has three 16-b compare registers CMPR1, CMPR2 and CMPR3 to control the individual duty cycle of the switches as shown in Fig. 16. The values that need to be loaded to these registers to generate symmetrical PWM pulses are given in Table IV. Necessary adjustments to the basic ON and OFF times of each switch are performed in the Dead Band units. The switch dead time is controlled by dead time control register DBTCON. The output PWM pulses are obtained by comparison of values in timer 1 counter register T1CNT and compare registers CMPR1-2-3. The Output Logic Units of the Event Manager Module determine the logic level, i.e., active high or active low, of each PWM output. The six output signals are available on dedicated PWM output pins PWM1 to PWM6. If odd numbered pin is used for driving top device then the corresponding even numbered pin should be used for the bottom device. The execution time of the control algorithm is less than $40 \mu \mathrm{s}$.

\section{EXPERIMENTAL RESULTS}

The control algorithm is tested for experimental verification on a $10 \mathrm{KW}$ three phase boost rectifier unit. The ac-line input is $415 \mathrm{~V}$ (line-to-line) $\pm 15 \%$, and the regulated dc output is $700 \mathrm{~V}$. The measured value of the line inductance is $7.5 \mathrm{mH} / \mathrm{phase}$. Switching frequency of the IGBT based (IPM Module) converter is chosen to be $10 \mathrm{KHz}$. The value of the boost inductance could be less if we could use higher switching frequency. However, the high power converters are generally switched at frequencies around $10 \mathrm{KHz}$, as in [2], so as to utilize the converter for maximum possible power output. Moreover, in order to operate the converter at a substantially higher frequency than $10 \mathrm{KHz}$ a DSP with higher CPU speed and lower ADC conversion time than TMS320F240 should be used. Otherwise the ADC conversion time, that is $6.6 \mu \mathrm{S}$ for each conversion in TMS320F240, becomes substantial compared to the loop time of the control algorithm. It may also be noted that an input voltage sensorless algorithm is less demanding on digital hardware as fewer numbers of analog to digital conversions are required. The computational burden on the controller is less as well because the design of phase lock loop (PLL) circuit is not required in this method.

The line currents $i_{g a}$ and $i_{g b}$ are sensed by "LEM" made Hall effect current sensors of model LA50. It has a turns ratio of 1:1000. For each current sensor the primary has two turns and the output of the current sensor has been terminated by a $100 \Omega$ resistance. The output voltage $V_{o}$ is isolated by high 

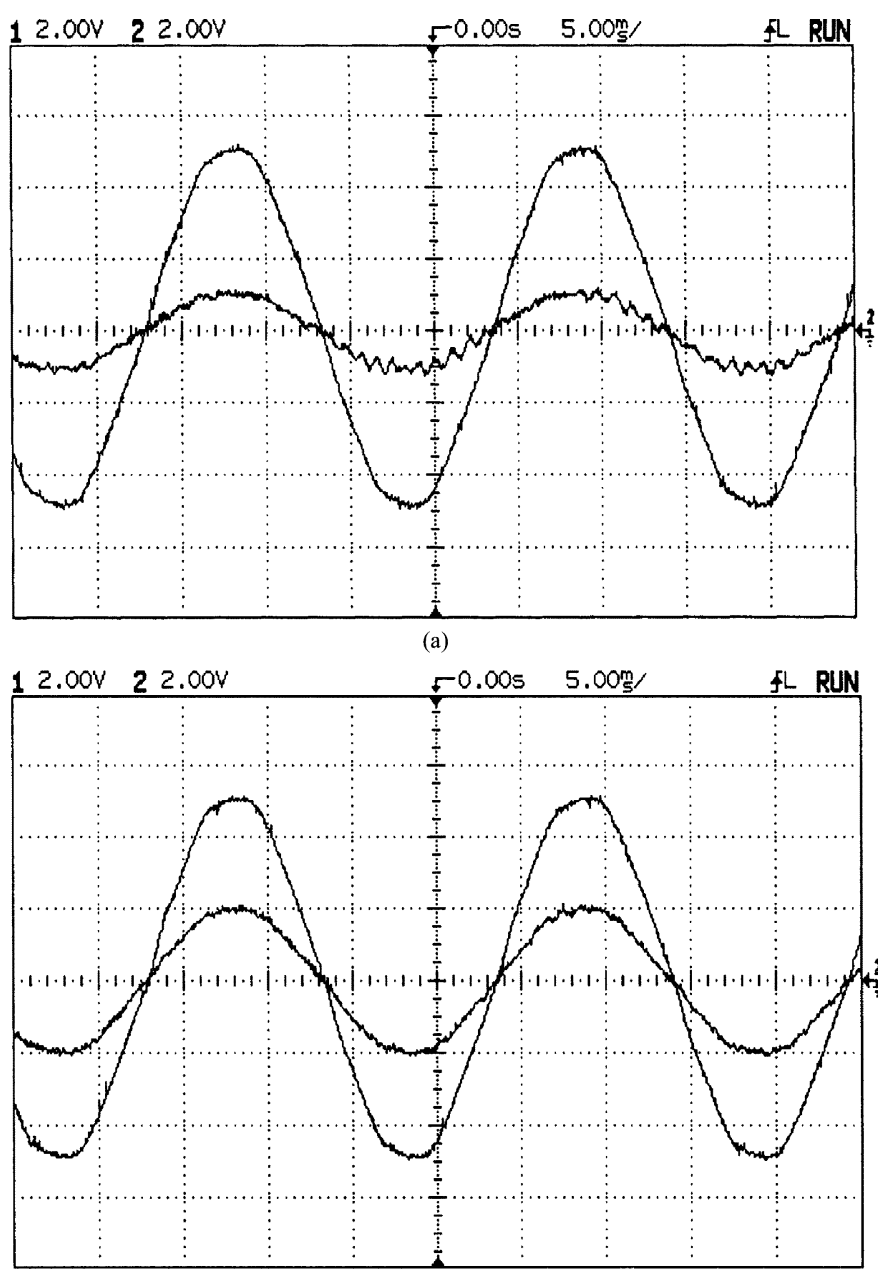

(b)

Fig. 21. Experimental results: $v_{g a}$ and $i_{g a}$ at $V_{a b}=415 \mathrm{~V}$ and $V_{o}=700 \mathrm{~V}$ (a) $2.8 \mathrm{~kW}$ (b) $5 \mathrm{~kW}$ Total harmonic Distortion (a) $5.6 \%$ (b) $2.9 \%$ Voltage Scale: 133.5 V/div Current Scale: 10.4 A/div Inductance/Phase: $7.5 \mathrm{mH}$ Power Factor: (a) 0.999 and (b) 0.999 .

CMR isolation amplifier HCPL 7800. The analog signals are scaled by 0.25 and dc shifted by $2.5 \mathrm{~V}$ in the analog signal conditioner board, before passing them on to analog input channels of TMS320F240. This has been done so as to make sure that the analog input channels of the DSP receive unipolar signals between $0-5 \mathrm{~V}$ range. Therefore the effective value of the current sense resistance is $R_{s}=0.05$.

Fig. 17 shows the frequency response plot of the voltage control transfer function $G_{v}(s)=\widetilde{V_{o}}(s) / \widetilde{V_{m}}(s)$ measured using Schlumberger 1250 frequency response analyzer (FRA) instrument. The nominal operating point of the converter is defined in Fig. 14.

It is also given as

$$
\begin{aligned}
& V_{\text {ga }}(\text { phase })=110 \mathrm{~V}(\mathrm{rms}), V_{o}=300 \mathrm{~V}, \\
& V_{m}=0.25 \mathrm{~V}, L=7.5 \mathrm{mH} / \text { phase }, \\
& R=100 \Omega, C=1650 \mu \mathrm{F}, R_{s}=0.05 \Omega .
\end{aligned}
$$

The analog modulating signal $\widetilde{V_{m}}$ of the FRA is converted to its digital equivalent using one of the spare ADC channels of TMS320F240 and then added to the nominal operating

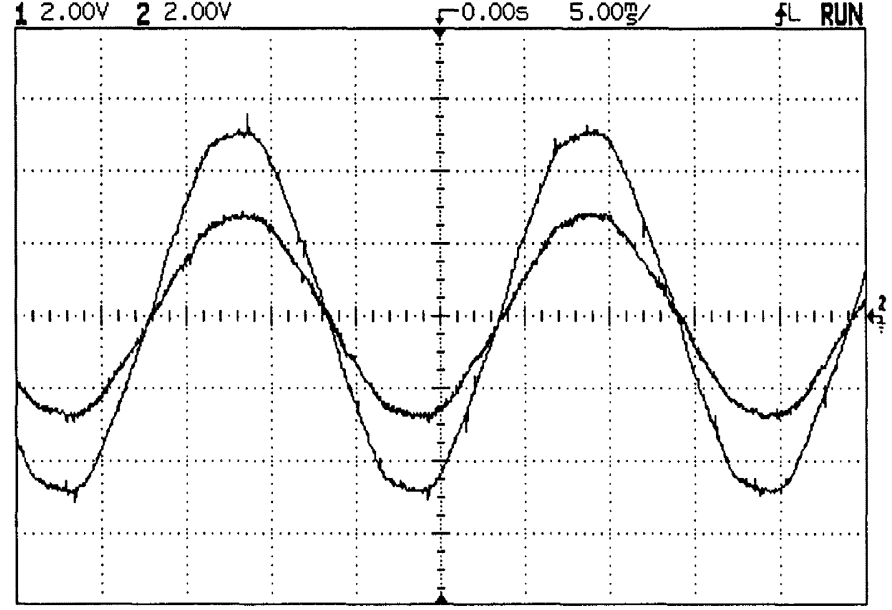

(a)

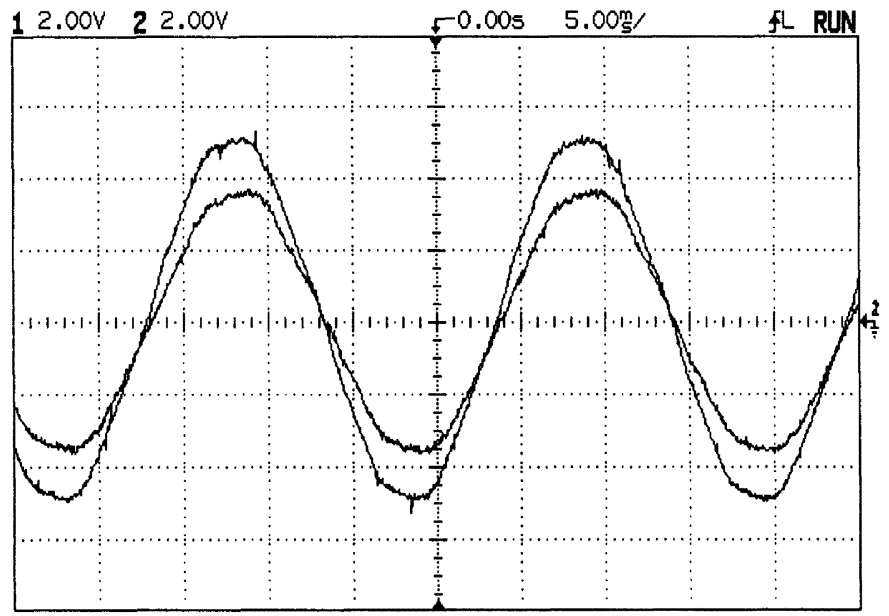

(b)

Fig. 22. Experimental results: $v_{g a}$ and $i_{g a}$ at $V_{a b}=415 \mathrm{~V}$ and $V_{o}=700 \mathrm{~V}$ (a) $7.5 \mathrm{~kW}$ (b) $9 \mathrm{~kW}$. Total harmonic Distortion $=$ (a) $2.51 \%$ (b) $2.4 \%$ Voltage Scale: $133.5 \mathrm{~V} /$ div Current Scale $=10.4 \mathrm{~A} /$ div Inductance $/$ Phase $=$ $7.5 \mathrm{mH}$ Power Factor = (a) 0.998 (b) 0.995.

reference $V_{m}$ inside the digital controller. For measurement, the analog signal $\widetilde{V_{m}}$ and the scaled output signal $\widetilde{V_{o}}$ are connected to the input and output channels of the FRA respectively. The frequency response plot of the same transfer function obtained through linear, small signal, low frequency analysis of the three phase boost rectifier is placed in the same figure (Fig. 17) for easy comparison. It can be seen that qualitatively the analysis and the measurement results match over the entire frequency range of the plot. However there exists a phase difference between analysis and measurement results in the frequency range above $100 \mathrm{~Hz}$. This difference is due to the phase contribution from the pole introduced by the zero order hold circuit of the ADC of TMS320F240. The pole is located approximately at $1590 \mathrm{~Hz}$, if we model zero order hold as a low pass filter at low frequency. This correction, when taken into account, makes the analytical and measurement results of the frequency response of $G_{v}(s)$ follow each other very closely.

Therefore we can conclude that an accurate low frequency model of the three phase boost rectifier can be developed by following the standard small signal analysis methods of a current mode controlled dc-dc converter if the nominal dc operating point is chosen as $V_{g}=1.5 V_{g a} \sin \left(45^{\circ}\right)$. 


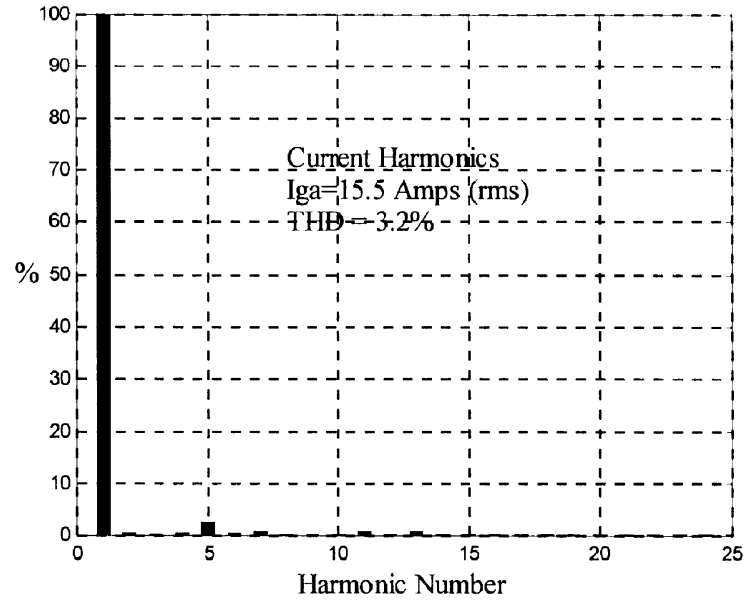

Fig. 23. Measurement result from LEM HEME ANALYST 2060: Harmonic spectrum of the input current (RMS 15.5 Amp, THD 3.2\%) at maximum load $(10 \mathrm{Kw}, 700 \mathrm{~V} \mathrm{DC})$

Figs. 18-20 show different control variables through 12-b bipolar digital to analog converter (DAC) outputs of the DSP control board.

In Fig. 18(a) we can see the sequence of sector change that occurs under closed loop condition with respect to currents $i_{g a}$ and $i_{g b}$. Fig. 18(b) shows the sequence of sector change with respect to $i_{g \alpha}$ and $i_{g \beta}$. They prove the validity of the self-synchronization logic described in Section II.

In Section II we have indicated that the control algorithm based on the sector information uses a set of simultaneous equations to calculate the switching time durations. Fig. 19(a) and Fig. 19(b) show the profile of the switching times $T_{\alpha}, T_{\beta}$ and $T_{1}, T_{2}$ that are obtained after solving those equations in real time over a line frequency period of $i_{g \alpha}$.

Fig. 20(a) shows the signal that indicates in real time the selection of the set of simultaneous equations for calculation of $T_{1}$, $T_{2}$. It may be noted that the sectors 1-3-4-6 have been mapped as low level and sectors 2A-2B-5A-5B have been mapped as high level. The execution time of the control algorithm in DSP TMS320F240 is less than $40 \mu \mathrm{s}$, as can be seen from Fig. 20(b).

Fig. 21(a) and (b) show the phase voltage and phase current waveforms under regulated dc voltage of $700 \mathrm{~V} \mathrm{dc}$, at two different load conditions of $2.5 \mathrm{~kW}$ and $5 \mathrm{~kW}$, respectively.

Under same input and output voltage conditions Fig. 22(a) and (b) show high power factor operation at loads of $7.5 \mathrm{~kW}$ and $9 \mathrm{Kw}$.

The input current and voltage waveforms are analyzed for power factor and total harmonic distortion (THD) results by "LEM" made HEME ANALYST $2060 \mathrm{~m}$. Power factor greater than 0.995 and THD less than $6 \%$ are achieved on input current over a load range of $20 \%$ to $110 \%$ The harmonic spectrum of the input current at maximum load under rated operating condition is shown in Fig. 23.

The dynamic response of the output dc voltage at step change of the load resistance from $116 \Omega$ to $58 \Omega$ is shown in Fig. 24(a). For the same step change in load resistance the dynamic response of the input current is shown in Fig. 24(b).

One of the disadvantages of this method is that it requires certain minimum load to be applied on the converter output so as
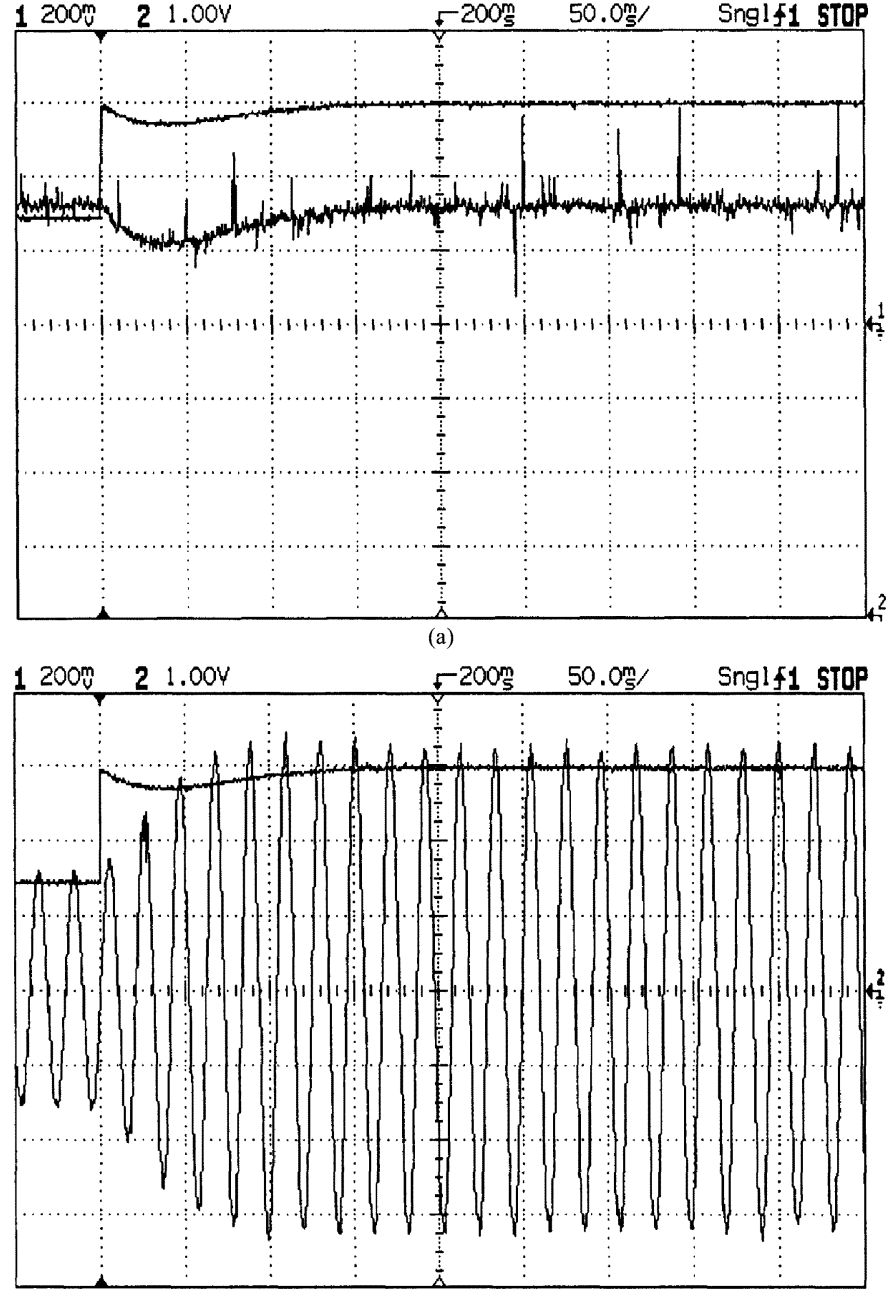

(b)

Fig. 24. Experimental Results: dynamic Response of the (a) output dc voltage at a step change in the load resistance Channel 1: load current, Scale $($ ch1 $)=4 \mathrm{~A} /$ div Channel 2: output de voltage $V_{o}$, Scale (ch2): $125 \mathrm{~V} / \mathrm{div}$ (b) input phase current at a step change in the load resistance Channel 1: Load current, Scale $(\operatorname{ch} 1)=4 \mathrm{~A} /$ div Channel 2: Input phase current $i_{g a}$, Scale (ch2): $5.2 \mathrm{~A} / \mathrm{div}$ load resistance initial: $116 \mathrm{ohm}$, Load Resistance Final: $58 \mathrm{ohm}$, Inductance $/ \mathrm{Phase}=7.5 \mathrm{mH}$

to operate stably as has been shown analytically in Section IV of this paper. It is also important that the inductive drop is substantially low compared to the input voltage so that (6) and (7) can be valid for every switching period of the converter. If such a condition is not satisfied there will be steady state error in phase angle of input current. Therefore, it will be better to operate the converter at as high switching frequency as possible, under the constraint of the power circuit design, so that the boost inductance can be of low value. The other limitation of this method is that if the input voltage itself contains harmonics then the input current being proportional to the input voltage will contain the those harmonics that are within its bandwidth.

\section{CONCLUSION}

This paper describes the DSP based implementation of a discrete current mode control algorithm that performs high power factor rectification for a three phase boost converter. In this controller input voltage sensing is not required, because switching 
pulses get self-synchronized with the frequency and phase of the input voltage. There is no need to use conventional PLL, as the controller works in stationary reference frame. Two decoupled fixed frequency current mode controllers generate the switching instants for the equivalent single phase boost rectifiers. A combined switching strategy is developed in the form of space vectors to simultaneously satisfy the timing requirements of both the current mode controllers in a switching period. The steady state stability condition of the digitally controlled boost rectifier has been derived. It is shown that if the nominal dc operating point is chosen as $V_{g}=1.5 V_{g a} \sin \left(45^{\circ}\right)$ then a low frequency model of the three phase boost rectifier can be developed by following the standard small signal modeling technique of a current mode controlled dc-dc converter.

The control algorithm is computationally simple. In TMS320F240 which has a clock frequency of $20 \mathrm{MHz}$ and ADC conversion time of $13.2 \mu \mathrm{s}(=6.6 \mu \mathrm{s} * 2)$, the control algorithm gets executed in less than $40 \mu \mathrm{s}$. In conclusion, it can be said that, this method of control of three phase high power factor Boost rectifier provides comparable or better performance over existing methods with a much simpler control structure.

\section{APPENDIX I}

The simulation model of the three phase-three wire PWM converter of Fig. 1 is based on the following equations:

$$
\begin{aligned}
& L \frac{d i_{g a}}{d t}=v_{g a}-v_{r a} \\
& L \frac{d i_{g b}}{d t}=v_{g b}-v_{r b} \\
& L \frac{d i_{g c}}{d t}=v_{g c}-v_{r c} \\
& C \frac{d V_{o}}{d t}=\left(i_{g a} U_{a}+i_{g b} U_{b}+i_{g c} U_{c}\right)-\frac{V_{o}}{R}
\end{aligned}
$$

where

$$
\begin{aligned}
v_{r a} & =0.5 V_{0} M_{a}+v_{n o} \\
v_{r b} & =0.5 V_{0} M_{b}+v_{n o} \\
v_{r c} & =0.5 V_{0} M_{c}+v_{n o} \\
v_{n o} & =\frac{1}{3}\left[v_{g a}+v_{g b}+v_{g c}-0.5 V_{o}\left(M_{a}+M_{b}+M_{c}\right)\right] \\
U_{i} & =1 \text { if } S_{i} \text { is } O N \quad \text { and } \\
U_{i} & =0 \text { if } S_{i} \text { is OFF, i=a,b,c } \\
M_{i} & =1 \text { if } S_{i} \text { is ON and } \\
M_{i} & =-1 \text { if } S_{i} \text { is OFF, } i=a, b, c .
\end{aligned}
$$

\section{REFERENCES}

[1] V. Vlatkovic and D. Borojevic, "Digital-signal-processor-based control of three phase space vector modulated converters," IEEE Trans. Ind. Electron., vol. 41, pp. 326-332, June 1994.

[2] M. Malinowski, M. P. Kazmeirkowski, S. Hansen, F. Blaabjerg, and G. D. Marques, "Virtual-flux-based direct power control of three-phase PWM rectifiers," IEEE Trans. Ind. Applicat., vol. 37, pp. 428-436, May 2001.
[3] I. Agirman and V. Blasko, "A novel control method of a VSC without AC line voltage sensors," in Proc. IEEE-IAS Annual Meeting, vol. 4, 2001, pp. 2175-2180.

[4] M.-Y. Chang, J.-Y. Lin, and Y.-Y. Tzou, "DSP-based fully digital control of a ac/dc converter with a nonlinear digital current mode control," in Proc. PESC'96 Conference, 1996, pp. 1702-1708.

[5] S. Hiti and D. Boroyevich, "Control of front-end three-phase boost rectifier," in Proc. APEC'94 Conference, 1994, pp. 927-933.

[6] J. P. Gegner and C. Q. Lee, "Linear peak current mode control: a simple active power factor correction control technique for continuous conduction mode," in Proc. PESC'96 Conference, June 1996, pp. 196-202.

[7] D. Maksimovic, Y. Jang, and R. Erickson, "Nonlinear-carrier control for high power factor boost rectifiers," in Proc. APEC'95 Conference, 1995, pp. 635-641.

[8] S. Chattopadhyay, V. Ramanarayanan, and V. Jayashankar, "A predictive switching modulator for current mode control of high power factor boost rectifier," in Proc. PESC'O0 Conference, June 18-23, 2000, pp. 371-376.

[9] S. Buso, P. Mattavelli, L. Rossetto, and G. Splazzi, "Simple digital control improving dynamic performance of power factor preregulators," IEEE Trans. Power Electron., vol. 13, pp. 814-823, Sept. 1998.

[10] S. Hsu, A. Brown, L. Rensink, and R. D. Middlebrook, "Modeling and analysis of switching dc-to-dc converters in constant-frequency currentprogrammed mode," in Proc. PESC'79 Conference, June 18-22, 1979, pp. 284-301.

[11] S. Hiti, D. Boroyevich, and C. Cuadros, "Small signal modeling and control of three-phase PWM converters," in Proc. IAS'94 Conference, vol. 2, 1994, pp. 1143-1150.

[12] R. D. Middlebrook, "Topics in multiple-loop regulators and current-mode programming," IEEE Trans. Power Electroni., vol. PE-2, pp. 109-124, Apr. 1987.

[13] TMS320C24x DSP Controllers Peripheral Library and Specific Devices_Reference Set_Volume 2, December 1997.

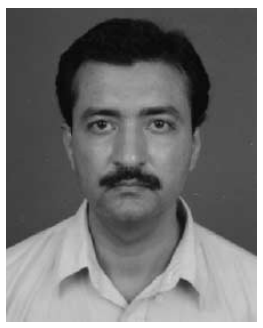

Souvik Chattopadhyay received the B.E. degree from Bengal Engineering College, Howrah, India, in 1988, and the M.S. and Ph.D. degrees from the Indian Institute of Science, Bangalore, India, in 1990 and 2002, respectively.

$\mathrm{He}$ is currently an Assistant Professor in the Department of Electrical Engineering, Indian Institute of Technology, Madras. Between 1991 and 1995, he was with the M/s Crompton Greaves Ltd., Bombay, India, as a Research and Development Engineer in the Power Electronics Group of R\&D (Electricals). Between 1996 and 1998, he was with M/s Cegelec India Ltd., Delhi, India, as a Project Engineer-Industrial Drives. He was a part of the commissioning team for phase IV modernization of the TISCO Hot Strip Mill, Jamshedpur, India. His research interests include design, analysis, control, and modeling of power converters from PFC circuits, and active filter systems.

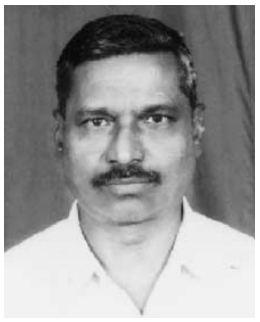

V. Ramanarayanan received the B.E. degree from the the University of Madras, Madras, India, in 1970, the M.E. degree from Indian Institute of Science, Bangalore, in 1975, and the Ph.D. degree from the California Institute of Technology, Pasadena, in 1986.

He is a Professor and Chairman of the Department of Electrical Engineering, Indian Institute of Science, Bangalore. He has held positions in industry as a Senior Design Engineer and Chief of R\&D with M/s Larsen and Toubro Ltd. (1970-1979) and NGEF Ltd. (1979-1982). His areas of interest are power electronics, industrial drives, switched-mode power conversion, and power quality issues. He is a Consultant to several industries in related areas. 